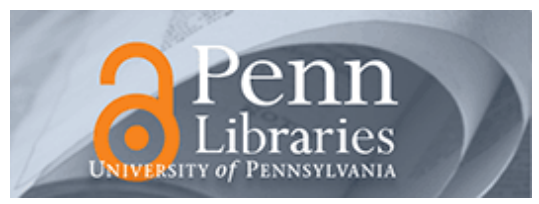

University of Pennsylvania

ScholarlyCommons

\title{
$5-2015$
}

\section{The Impact of Time at Work and Time off From Work on Rule Compliance: The Case of Hand Hygiene in Healthcare}

Hengchen Dai

University of Pennsylvania

Katherine L. Milkman

University of Pennsylvania

David. A. Holfman

Bradly. R. Staats

Follow this and additional works at: https://repository.upenn.edu/oid_papers

Part of the Labor Economics Commons, and the Performance Management Commons

\section{Recommended Citation}

Dai, H., Milkman, K. L., Holfman, D. A., \& Staats, B. R. (2015). The Impact of Time at Work and Time off From Work on Rule Compliance: The Case of Hand Hygiene in Healthcare. Journal of Applied Psychology, 100 (3), 846-862. http://dx.doi.org/10.1037/a0038067

This article may not exactly replicate the final version published in the APA journal. It is not the copy of record.

This paper is posted at ScholarlyCommons. https://repository.upenn.edu/oid_papers/234

For more information, please contact repository@pobox.upenn.edu. 


\title{
The Impact of Time at Work and Time off From Work on Rule Compliance: The Case of Hand Hygiene in Healthcare
}

\begin{abstract}
To deliver high-quality, reliable, and consistent services safely, organizations develop professional standards. Despite the communication and reinforcement of these standards, they are often not followed consistently. Although previous research suggests that high job demands are associated with declines in compliance over lengthy intervals, we hypothesized-drawing on theoretical arguments focused on fatigue and depletion-that the impact of job demands on routine compliance with professional standards might accumulate much more quickly. To test this hypothesis, we studied a problem that represents one of the most significant compliance challenges in health care today: hand hygiene. Using longitudinal field observations of over 4,157 caregivers working in 35 different hospitals and experiencing more than 13.7 million hand hygiene opportunities, we found that hand hygiene compliance rates dropped by a regression-estimated 8.7 percentage points on average from the beginning to the end of a typical 12-hr work shift. This decline in compliance was magnified by increased work intensity. Further, longer breaks between work shifts increased subsequent compliance rates, and such benefits were greater for individuals when they had ended their preceding shift with a lower compliance rate. In addition, (a) the decline in compliance over the course of a work shift and (b) the improvement in compliance following a longer break increased as individuals accumulated more total work hours the preceding week. The implications of these findings for patient safety and job design are discussed.
\end{abstract}

\section{Keywords}

workplace compliance, job demands, fatigue, work recovery, job design

\author{
Disciplines \\ Labor Economics | Performance Management
}

\section{Comments}

This article may not exactly replicate the final version published in the APA journal. It is not the copy of record. 
The Impact of Time at Work and Time off from Work on Rule Compliance:

The Case of Hand Hygiene in Healthcare

Hengchen Dai ${ }^{1}$ and Katherine L. Milkman ${ }^{1}$

The Wharton School

University of Pennsylvania

Philadelphia, Pennsylvania 19104

David A. Hofmann and Bradley R. Staats

The Kenan-Flagler Business School

The University of North Carolina at Chapel Hill

Chapel Hill, North Carolina 27599

${ }^{1}$ We thank Joe Simmons and participants at the Center for Health Incentives and Behavioral Economics Seminars for helpful feedback. We also thank Proventix (in particular, David Sellers and Elizabeth Pembleton) without whose assistance this project would not have been possible. Finally, we thank the Wharton Dean's Research Fund and the Wharton Risk Management and Decision Processes Center for funding support. 


\begin{abstract}
In order to deliver high quality, reliable, and consistent services safely, organizations develop professional standards. Despite the communication and reinforcement of these standards, they are often not followed consistently. Although previous research suggests that high job demands are associated with declines in compliance over lengthy intervals, we hypothesized - drawing on theoretical arguments focused on fatigue and depletion - that the impact of job demands on routine compliance with professional standards might accumulate much more quickly. To test this hypothesis, we studied a problem that represents one of the most significant compliance challenges in healthcare today: hand hygiene. Using longitudinal field observations of over 4,157 caregivers working in 35 different hospitals and experiencing more than 13.7 million hand hygiene opportunities, we found that hand hygiene compliance rates dropped by a regression-estimated 8.5 percentage points on average from the beginning to the end of a typical, 12-hour work shift. This decline in compliance was magnified by increased work intensity. Further, longer breaks between work shifts increased subsequent compliance rates, and such benefits were greater for individuals when they had ended their preceding shift with a lower compliance rate. In addition, (a) the decline in compliance over the course of a work shift and (b) the improvement in compliance following a longer break increased as the caregiver accumulated more total work hours the preceding week. The implications of these findings for patient safety and job design are discussed.
\end{abstract}

Word count: 234

Keywords: workplace compliance, job demands, fatigue, work recovery, job design 
In order to deliver high quality, reliable, and consistent services safely, organizations develop professional standards. These standards may be adopted from external agencies (e.g., professional industry groups, external regulators) or developed through the internal documentation and proliferation of best practices. There are often significant benefits associated with adopting professional standards. For instance, within healthcare, implementing a 19-item surgical safety checklist recommended by the World Health Organization (WHO) was found to reduce the rate of deaths and inpatient complications by $47 \%$ and $36 \%$ respectively (Haynes et al., 2009). As such, the importance of complying with professional standards is frequently communicated, and actual compliance is reinforced and rewarded within organizations.

However, rates of compliance with professional standards are not always high. Task pursuit in organizations involves multiple, and often competing goals, some of which may be perceived as more pressing, proximal, and urgent than others (e.g., Schmidt \& DeShon, 2007). In addition, workers also experience physical, cognitive, and emotional demands that can deplete their self-regulatory resources (e.g., Demerouti, Bakker, Nachreiner, \& Schaufeli, 2001). These realities of work can lead to the violation of professional standards, particularly those standards that may be perceived as relatively minor in importance and that require frequent, routine compliance (see, for example, Hofmann \& Frese, 2011; Hofmann \& Stetzer, 1996; Turner, Chmiel, Hershcovis, \& Walls, 2010).

Although previous research has linked job demands - such as work overload, time pressure, and emotional demands - to job performance, work engagement, absenteeism and compliance with safety standards (e.g., Bakker, Demerouti, de Boer, \& Schaufeli, 2003; Nahrgang, Morgeson, \& Hofmann, 2011; Schaufeli, Bakker, \& Van Rhenen, 2009), virtually all of this prior research has focused on the relationship between broad, long-term, self-reported 
perceptions of work demands and compliance. ${ }^{2}$ Drawing on prior research and theories investigating fatigue and self-regulatory depletion, we investigated the degree to which the impact of job demands may accumulate more quickly, perhaps even as quickly as over the course of a single work shift. To our knowledge, this is the first study investigating whether accumulated work demands can impact rule compliance over the course of a single day as opposed to over weeks, months or years. If work demands have a more immediate impact on routine compliance, then there are significant implications for work design, as interventions aimed at addressing long-term work engagement and demands (e.g., Campion, 1988) might need to be augmented with interventions designed to alter the daily pace of work.

If self-regulatory depletion and fatigue underlie the degradation of compliance, then time away from work allowing for recovery should improve subsequent compliance. Thus, we also investigated the impact of time off work on compliance during the next work cycle. The implications of breaks for employee performance have only been explored in terms of employees' performance on their primary task (e.g., Fritz \& Sonnentag, 2006; Binnewies, Sonnentag, \& Mojza, 2010). Thus, little is known about how time away from work may affect employee performance on important secondary tasks, including routine compliance with professional guidelines, which we explore in this paper.

\section{Accumulated Work Demands and Performance on Secondary Task Compliance}

As noted above, employees in contemporary organizations are expected to pursue multiple, and sometimes competing goals simultaneously (Schmidt \& DeShon, 2007) and to

${ }^{2}$ For example, Hofmann and Stetzer (1996) investigated general perceptions of work overload and an aggregate measure of unsafe behavior “over the preceding 12-months.” Similarly, Turner et al. (2010) investigated the relationship between general perceptions of role overload and safety events over a 12-month period. 
endure heavy work demands (e.g., time pressure, quality pressure, work overload, role ambiguity, and emotional strain; Bakker \& Demerouti, 2007; Demerouti et al., 2001). Although high job demands have the potential to energize employees (Karasek \& Theorell, 1990), they typically have significant psychological and physiological costs over time on job performance and employees' wellbeing (Crawford, LePine, \& Rich, 2010; Demerouti et al., 2001; Schaufeli et al., 2009). We propose that these demands may take a more immediate toll on seemingly secondary tasks, including compliance with professional guidelines, for two reasons.

First, when workers are faced with the pursuit of multiple goals in the context of high job demands, past research suggests that they may focus their attention on the most salient, proximal, and rewarded goals (Schmidt \& DeShon, 2007). Hockey $(1993,1997)$ termed this a "performance protection strategy" suggesting that workers attempt to maintain effective primary task performance by increasing their effort expenditure and cognitive processing devoted to these tasks. With greater effort expended on primary tasks, performance on secondary tasks may suffer as effort and resources are directed away from these tasks. Consequently, although performance on primary tasks can be maintained as employees become increasingly fatigued, past research has shown that employees exhibit selective impairment on low-priority task components ("subsidiary task failure"), such as the neglect of subsidiary activities and narrowing of attention (Hockey, 1993, 1997).

The second reason we predict job demands may take an immediate toll on secondary tasks is the fatigue induced by both the continuous pursuit of multiple goals and the exposure to high work demands, which can tax and deplete self-regulatory resources (Baumeister, Bratslavsky, Muraven, \& Tice, 1998). Just as the repeated exercise of our muscles leads to physical fatigue, repeated use of "executive resources" (or cognitive resources that allow people 
to control their behaviors, desires, and emotions) produces a decline in an individual's selfregulatory capacity (Hagger, Wood, Stiff, \& Chatzisarantis, 2010; Baumeister et al., 1998). Importantly, impaired self-regulatory capacity diminishes one's ability to resist temptation and control one's impulses (Kouchaki \& Smith, 2014; Linder et al., 2013) and increases one's desire to avoid exerting further effort (Baumeister et al., 1998; Danziger, Levav, \& Avnaim-Pesso, 2011). Notably, this avoidance of effort has been linked to employees' routine violations of organizational rules and their tendency to "cut corners" (Reason, 1995; Reason, Parker, \& Lawton, 1998). Thus, we argue that performing secondary tasks requires some combination of effort and self-regulatory resources and that when individuals are fatigued and these resources are depleted, performance on secondary tasks will decline.

\section{Hand Hygiene Compliance in Healthcare}

Prior to formulating our specific hypotheses, it is import to introduce the context where the current research was undertaken because research related to this particular domain also informs our hypotheses. The current research focuses on a specific violation of professional standards that has the potential to harm both employees and service recipients; namely: deviation from hand hygiene standards in healthcare settings. Maintaining hand hygiene among healthcare workers is widely accepted as one of the most effective means of reducing patients' healthcareassociated infections, which affect one in every 20 hospitalized patients and are one contributing factor to the estimated 100,000 healthcare-related deaths in the United States each year (CDC, 2002; WHO, 2009). Nevertheless, systematic reviews of hand hygiene guideline compliance suggest that compliance rates are below 50\% in most healthcare settings (CDC, 2002).

Healthcare service workers (e.g., nurses and physicians) are among the many professionals whose occupations are characterized by high job demands (Dollard \& McTernan, 
2011; Houtman \& Kompier, 1995). For example, healthcare workers frequently make consequential, life-and-death decisions and are required to take action under time pressure. Also, emotional demands are common in the healthcare industry: caregivers interact regularly with vulnerable patients and must frequently engage in emotion regulation (e.g., taking care to display only appropriate emotions; Bakker, Schaufeli, Sixma, Bosveld, \& Van Dierendonck, 2000).

\section{Hypothesis Development: Work Demands and Rule Compliance}

Given their continuous exposure to intensive daily demands, it is anticipated that as their work shifts proceed, healthcare workers become increasingly focused on their primary tasks and most pressing goals while simultaneously being drained of the self-regulatory resources required to attend to seemingly more minor tasks. In healthcare settings, primary tasks are those that directly contribute to "production," such as disease diagnosis, patient assessment, and medication distribution, whereas hand hygiene is perceived to be one of many secondary tasks. Further evidence suggests that healthcare professionals do not view hand hygiene as a primary goal. First, low rates of compliance suggest this. Second, industry guidelines advise caregivers to sanitize their hands at an extremely high daily frequency, so each hand cleansing likely feels as though it has a trivial impact on infection rates (Erasmus et al., 2009; Hugonnet \& Pittet, 2000).

Connecting the above arguments, we propose that work demands result in a focus on accomplishing primary tasks and in depleted self-regulatory capacity, which together reduce individuals' capacity to expend effort on secondary tasks (e.g., compliance with hand hygiene guidelines). We rely on the time a caregiver has spent at work as a proxy for how long he or she has been continuously exposed to a demanding work environment ${ }^{3}$ and predict that workers will

${ }^{3}$ Past research suggests that the amount of time individuals spend performing tasks that require attention and mental resources is a reliable predictor of their subsequent ability to expend executive resources (See, Howe, 
exhibit greater reductions in hand hygiene compliance the longer they have been exposed to this environment over the course of a typical work shift. Specifically, we hypothesize the following: Hypothesis 1: As caregivers advance through a shift, their compliance with hand hygiene standards will decrease.

As described previously, high job demands are produced by challenging conditions at work including time pressure, heavy workloads, fast-paced assignments, and long work hours. Dealing with all such job demands requires physical and/or mental resources (Demerouti et al., 2001). For example, high intensity work, as measured by high workloads and fast-paced jobs, has been shown to produce emotional exhaustion and burnout and to reduce task performance and work engagement (Hansez \& Chmiel, 2010; Nahrgang et al., 2011; Sonnentag. Kuttler, \& Fritz, 2010). These findings suggest that each hour of engagement in a high-intensity work environment should consume more resources and cause greater depletion than each hour of engagement in a lower-intensity setting. Building on this idea, we expect that high work intensity (e.g., characterized by employees performing demanding tasks at a high frequency) will exacerbate the effects of time at work on fatigue and depletion. This in turn should produce a steeper decline in hand hygiene compliance over the course of a shift than would be expected in a work environment with lower intensity. We specifically hypothesize the following:

Hypothesis 2: Compliance with hand hygiene standards will decrease faster over the course of a shift when caregivers experience a higher level of work intensity.

\section{Time off between Shifts as Replenishment}

\footnotetext{
Warm, \& Dember, 1995; Danziger et al., 2011; Welsh \& Ordóñez, 2014). In the healthcare context, surveys among caregivers have shown that they feel more exhausted at the end of a longer shift than a shorter shift (Rogers, Hwang, \& Scott, 2004; Stimpfel, Sloane, \& Aiken, 2012).
} 
When intense work environments focus employees' attention on primary tasks and deplete their self-regulatory capacity (Demerouti et al., 2001; Hockey, 1997), one way to recharge is by discontinuing physically or cognitively taxing activities and engaging in pursuits that promote recovery (e.g., taking a break to rest, sleeping, taking a vacation; Trougakos, Beal, Green, \& Weiss, 2008; Sonnentag et al., 2008; Fritz \& Sonnentag, 2006; Westman \& Eden, 1997). Consistent with our focus on depletion over the course of a single shift, we investigate the recovery benefits of relatively short periods of time off between shifts ( 7 hours to 4.5 days) as these capture the typical amount of time that people take off between shifts.

Considerable empirical evidence suggests that sleep and even short weekend periods of time off can help employees overcome the fatigue they accumulate throughout their workdays, contributing to desirable performance-related outcomes, well-being, positive emotional experiences, and job satisfaction (Binnewies et al., 2010; Fritz \& Sonnentag, 2005; Sonnentag et al., 2008; Westman \& Eden, 1997). We therefore predict that time off between successive work shifts should replenish the executive resources that we have argued are needed to comply with professional standards, with longer breaks resulting in increased recovery. Time off should, therefore, predict subsequent hand hygiene compliance. We hypothesize the following: Hypothesis 3: The longer a caregiver's time off between consecutive work shifts, the higher her compliance will be with hand hygiene standards on her next shift.

Notably, numerous past studies have shown that although recovery activities (e.g., taking a break, experiencing positive emotions, or consuming a glucose drink) can have significant restorative benefits for individual who are depleted, these same activities have less impact for those individuals who are not depleted (Gailliot et al., 2007; Tice, Baumeister, Shmueli, \& Murave, 2007; Tyler \& Burns, 2008). For example, in a recent review of research on the 
relationship between blood glucose levels and depletion, Gailliot and Baumeister (2007) posited that increased blood glucose levels are better facilitators of self-regulation for individuals who are more depleted. Given our theory that lower hand hygiene compliance at the end of a work shift results from more extreme caregiver fatigue and depletion, we predict that caregivers with lower compliance rates at the end of one shift should benefit more from more time off before their next shift. Specifically, we hypothesize:

Hypothesis 4: The positive relationship between time off between shifts and compliance on a caregiver's next shift will be stronger the lower a caregiver's compliance was at the end of her previous shift.

\section{Spillover Effects of Accumulated Work Demands}

Not only may work demands within a day affect performance negatively, but recent studies suggest that work demands can accumulate over short periods - such as the work week in order to produce harmful spillover effects, damaging employees' performance on subsequent work shifts (e.g., Kc \& Terwiesch, 2009; Staats \& Gino, 2012). For example, Kc and Terwiesch (2009) showed that operational performance in a cardiac care unit was negatively impacted by the accumulated load that the unit experienced over the days preceding the current shift. Although previously unexplored, this line of thought suggests that within-shift degradation of performance may be further accelerated by heavy work demands in the recent past. As a result, we expect that working for one hour on a given shift would be more exhausting if a caregiver has worked more hours and thus been exposed to more work demands over her previous several shifts. Thus, we hypothesize the following: 
Hypothesis 5: Compliance with hand hygiene standards will decrease faster over the course of a given shift the more total hours a caregiver spent at work in the several days that preceded it.

As described above, past research has shown that depleted individuals benefit more from recovery activities (e.g., taking a break, consuming a sugary drink) than individuals who are not depleted (e.g., Gailliot et al., 2007; Tice et al., 2007). This logic should apply not only to the work demands within a single shift, but also the demands over the recent past. Since caregivers who had greater exposure to work demands across their previous shifts are likely to feel more fatigued than caregivers who had less exposure to work demands, we predict that the total amount of time caregivers spent at work in the days leading up to a given shift will exacerbate the benefits of lengthier breaks from work. Specifically, we hypothesize the following:

Hypothesis 6: More time off between shifts will do more to improve compliance on a caregiver's subsequent shift the more total hours a caregiver spent at work in the several days that preceded it.

\section{The Organizational Setting and Data}

\section{Setting}

To explore our research questions we use data from Proventix, a company that focuses on helping healthcare providers improve their hand hygiene. Proventix uses radio frequency identification (RFID) technology to monitor hand hygiene activity in healthcare settings by attaching a communication unit (CU) to conventional dispensers of hand soap and hand sanitizer. Caregivers wear active RFID badges along with their standard hospital identification, which track their location and behavior. Both the date and time when a caregiver enters the area 
monitored by a given dispenser as well as whether or not the caregiver uses the corresponding dispenser are recorded.

Hand hygiene is expected upon both entry into and exit from patient rooms (Steed et al., 2010) based on recommendations from the WHO and the Joint Commission Center for Transforming Healthcare (WHO, 2009; JCCTH, 2013). Following these recommendations, Proventix has developed a standardized measurement system to identify hand hygiene opportunities and calculate compliance rates among healthcare professionals. The basic unit of observation when calculating compliance, which we will call an "episode," requires a caregiver to stay in a patient's room for 20 seconds or longer - a length of time that Proventix has deemed through expert consultation is sufficient for hand hygiene to be clinically relevant. The room entry and room exit associated with an episode are classified as hand hygiene opportunities. In order to be deemed compliant for a given opportunity, caregivers are required to sanitize their hands within a 90-second window surrounding the hand hygiene opportunity in question (i.e., 60 seconds before and 30 seconds after a room entry; 30 seconds before and 60 seconds after a room exit). Proventix thoroughly briefs caregivers on how to be credited for hand cleansings.

\section{Data}

Proventix provided us with data collected from all of the 60 units at 37 hospitals that had installed their technology as of February 2013. This data tracked each of the 4,211 unique caregivers in these hospital units who had received an active RFID badge to track their hand hygiene compliance prior to February 28, 2013. The dates when the Proventix monitoring system was rolled out varied across hospital units and ranged from January 2010 to October 2012. For each hand hygiene opportunity (either a room entry or a room exit) experienced by each caregiver, our data set records: (a) the date and time the hand hygiene opportunity occurred, (b) 
whether or not a given caregiver sanitized her hands, and (c) how many times she sanitized her hands during the 90-second compliance window associated with the given hand hygiene opportunity. In total, our dataset documents 14,286,448 unique hand hygiene opportunities. Prior to releasing these data, Proventix deleted all caregiver names and hospital names and assigned unique, anonymous identification numbers to each caregiver within each hospital. We dropped a number of problematic observations $(N=76,298)$ before analyzing these data (e.g., duplicate observations, observations that did not involve caregivers, etc.). See Appendix A for details on our data exclusion criteria. Note that relaxing any of our criteria for improving the quality and reliability of our data would not qualitatively alter our results in significance or magnitude.

Since we did not have access to caregivers' shift schedules, we inferred the start and end time of each shift by calculating the interval separating each room exit from the next room entrance for each caregiver. When two consecutive episodes were at least seven hours apart, we identified the earlier episode as the last episode of the previous shift and the latter episode as the first episode of the next shift, ${ }^{4}$ consistent with the prevailing view in sleep research that seven or

\footnotetext{
${ }^{4}$ A limitation of this dataset is that we do not have information about what caregivers do when they are outside of patient rooms. They could theoretically still be at work following a seven hour gap in visits to patient rooms, although this is unlikely because the primary role of caregivers in the hospital units we study is to provide patient care, which requires entering and exiting patient rooms with relatively high frequency. However, if it were the case that some seven hour gaps in patient room visits did not signal time off between shifts, this would only attenuate our effects and result in a more conservative test of our hypothesis. We also varied the time interval used to segment successive shifts and found that our results were robust to alternative definitions (see the Electronic Companion Appendix B entitled Robustness Tests for details).
} 
more hours of sleep in a 24-hour period is sufficient for most people (Ferrara \& De Gennaro, 2001)..$^{5}$

Because we are interested in the effects of work-generated fatigue on hand hygiene compliance under normal work conditions, we excluded shifts lasting more than 13 hours from our analyses $(N=438,128)^{6}$ in light of differences in workload and patient conditions between normal shifts and extreme overtime shifts. When we examined shifts up to 36 hours as a robustness check, our results did not change meaningfully (see the Electronic Companion Appendix B entitled Robustness Tests for details).

Our final data set included 13,772,022 unique hand hygiene opportunities generated by 4,157 caregivers $\left(N_{\text {shifts }}=265,942\right)$ distributed across 35 hospitals and 56 hospital units. See Electronic Companion Appendix C for summary statistics describing hospital characteristics (e.g., location, size). Sixty five percent of the caregivers in our sample were nurses. The remaining caregivers included patient care technicians (12\%), therapists (7\%), physicians (4\%), and a handful of other types of employees (e.g., clinical directors, infection preventionists, etc.).

\section{Variables and Analyses}

\section{Variables}

${ }^{5}$ Of the 269,877 shifts identified in our data set, $46 \%$ began between 6 am and 8 am, and $28 \%$ began between $6 \mathrm{pm}$ and $8 \mathrm{pm}$. This suggests that our shift definitions were well-calibrated, as $7 \mathrm{am}$ and $7 \mathrm{pm}$ are the most common times for shift switches in hospitals (Rogers et al., 2004).

${ }^{6}$ Work shifts assigned to hospital nurses typically last either eight or twelve hours, with twelve-hour shifts becoming increasingly popular (Stimpfel et al., 2012). Healthcare work rotations usually also allow for a half-hour handoff period at the end of the previous caregiver's shift and the start of the incoming caregiver's shift (Rogers et al., 2004). Consistent with these common practices, more than $98 \%$ of the work shifts we observed lasted 13 hours or less. 


\section{Outcome Variable}

Compliance. Compliance was operationalized with a dichotomous indicator variable recording whether or not a caregiver washed her hands during a given hand hygiene opportunity. The mean compliance rate in our dataset was $38 \%$, which is nearly identical to the average compliance rate across hospitals reported by the WHO in 2009 of $39 \%$ (WHO, 2009).

\section{$\underline{\text { Primary Predictor Variables }}$}

Hours at Work. We calculated the time elapsed (in hours) since the start of a caregiver's work shift at the time of a given hand hygiene opportunity.

Hours off Work. We calculated the time elapsed (in hours) between two consecutive shifts for a given caregiver.

\section{Moderator Variables}

As would be expected given their frequent interactions with patients, nurses and patient care technicians generated $91 \%$ of all observed hand hygiene opportunities. Past research highlights that patient care is the most taxing component of a nurse's workload (Delucia, Ott, \& Palmieri, 2009; Battisto, Pak, Wood, \& Pilcher, 2009). ${ }^{7}$ To test the hypothesis that work intensity moderates the effects of hours at work on hand hygiene compliance (Hypothesis 2), we measured work intensity in two ways:

Moving Average Frequency of Patient Encounters. To calculate the hourly frequency at which a caregiver visited patient rooms leading up to a given hand hygiene opportunity, we

\footnotetext{
${ }^{7}$ A common measure of workload for nurses is the number of patients that a nurse oversees (Page, 2004),
} and nurses reported that most problems they encounter during nursing tasks occur at patients' bedside (Battisto, et al., 2009). 
divided the total number of episodes (or room visits) a caregiver had experienced by the number of hours the caregiver had been at work since he or she began a given shift.

Moving Average \% of Time in Patient Rooms. To calculate the fraction of time a caregiver spent in patient rooms per hour leading up to a given hand hygiene opportunity, we divided the total time (in hours) a caregiver had spent in patient rooms since the beginning of a given shift by the number of hours since the caregiver began the shift in question.

To test the hypothesis that hand hygiene compliance at the end of a caregiver's previous shift moderates the effect of hours off work on hand hygiene compliance during that caregiver's subsequent shift (Hypothesis 4), we created the following variable:

Compliance in the Final Hour of the Preceding Shift. For each shift, we calculated the average compliance rate associated with the last hour of the caregiver's preceding shift.

To test our hypotheses that heavy exposure to work demands in the recent past can produce spillover effects, exacerbating the impact of time at work (Hypothesis 5) and of time off from work (Hypothesis 6) on compliance, we created the following variable:

Total Hours at Work in the Past Week: For each shift, we calculated the total number of hours that a caregiver worked in the past seven calendar days prior to the start of the shift. We relied on a time window of seven days following Kc and Terwiesch (2009) and because caregivers typically work weekly schedules. ${ }^{8}$

${ }^{8}$ For shifts that occurred within seven days of a worker's first shift tracked by Proventix, we do not know the total hours a given caregiver worked during the previous seven days. Therefore, when we test hypotheses 5 and 6, our regression models (i.e., Models 7 and 8 in Table 3) do not include shifts that occurred within seven days of a worker's first shift. Note that all reported results remained meaningfully unchanged if we replaced total hours at work in the past week with the total number of hours at work in the past 14 days (i.e., two weeks), in the past five 


\section{$\underline{\text { Control Variables }}$}

For each hand hygiene opportunity, our analyses also included controls for (a) the duration of the corresponding episode (the time between room entry and exit), (b) an indicator for whether the episode involved a room entry (as opposed to a room exit), (c) the hour of the day, the day of the week, the month of the year, and the year when the episode occurred. Additional controls included the number of days since a caregiver first appeared in the Proventix data set and an indicator for whether Proventix had yet rolled out its RFID technology to all workers in a given unit (some caregivers pilot tested the technology prior to the full unit rollout, and their pilot data is included in our analyses). See Electronic Companion Appendix D for detailed information about how each of these control variables was constructed.

Table 1 provides means, standard deviations, and correlations for all variables included in our analyses.

\section{Analysis Strategy}

We employed generalized linear mixed-effects models with robust standard errors (using SAS Proc Glimmix) to analyze our data. Since hand hygiene opportunities were nested within caregivers and caregivers were nested within hospitals, we relied on three-level random intercept logistic regression models including both caregivers and hospitals random effects. Our dependent variable was an indicator for whether a given caregiver (level two) in a given hospital

\footnotetext{
days (the typical number of workdays per week) or during an even shorter time window (including two, three, or four days) prior to the start of a given shift. Interestingly, the total hours at work on a caregiver's previous day was not a statistically significant moderator of hours at work, suggesting that the spillover effects of accumulated work demands on compliance during caregivers' subsequent work shifts may take more than one day to manifest.
} 
(level three) sanitized her hands during a given hand hygiene opportunity (level one). Our primary predictor variables, moderators, and control variables (described above) are all level-one predictors. All continuous predictor variables (including our primary predictor variables, moderators, and control variables) were centered based on their mean values before they were included in our regression models.

To demonstrate the robustness of our results to alternative modeling strategies, we reanalyzed our data in several other ways. First, we re-analyzed our data using ordinary least squares regression models including fixed effects for each caregiver, and thus controlling for time-invariant characteristics of caregivers (e.g., an individual's propensity to comply). Whether we clustered our standard errors at the hospital level or at the caregiver level made little difference to our findings. Second, we employed two-level random intercept logistic regression models where we included the caregiver as a random factor at level two. Third, we employed two-level random intercept logistic regression models again with caregiver as a random factor at level two but with the inclusion of hospital fixed effects. Our results did not change meaningfully (e.g., all of the same findings were statistically significant) when we employed different analysis strategies and are all included in Appendix E.

\section{Results}

We first describe the effects of consecutive hours worked on hand hygiene compliance and then discuss the restorative effects of time off between shifts on compliance. Finally, we describe the impact of the total hours a caregiver worked in the past week on these effects. Note that all reported results are robust to numerous alternative specifications (see Appendix B). The Effect of Consecutive Hours Worked on Hand Hygiene Compliance 
Figure 1 depicts the average compliance rate across all data included in our analyses as a function of hours into a caregiver's shift, which dropped from $42.6 \%$ in the first hour of a shift to $34.8 \%$ in the last hour of a typical 12-hour shift (two sample test of proportions, $p<0.0001$ ). While the pattern described here and illustrated in Figure 1 is consistent with our hypothesis, it could be driven by other factors besides hours worked, so we turn to more controlled analyses.

Table 2 displays the results of a series of generalized linear mixed-effects regressions predicting hand hygiene compliance. Model 1 includes all aforementioned control variables and demonstrates that hours at work is significantly and negatively related to a caregiver's likelihood of complying with hand hygiene recommendations. Specifically, for every additional hour worked, the fitted odds that a caregiver was compliant decreased by a factor of 0.97 or $3 \%$ (accumulating to produce a 32\% decrease in the fitted odds of compliance over the course of a 12-hour shift or an 8.5-percentage point decrease in the rate of compliance for an average caregiver over the course of a 12-hour shift).

\section{$\underline{\text { Alternative Explanations for Our Findings besides Fatigue }}$}

Besides work-generated fatigue, there are a number of potential alternative explanations for our finding that compliance decreases over the course of a caregiver's shift. One is that caregivers interact with patients less frequently later in their shifts and thus view hand-washing as less important over time. ${ }^{9}$ Another potential alternative explanation is that as caregivers accumulate hand cleansings over the course of a shift, they might believe that additional hand cleansings are not as important or will dry out their skin. To address these alternative accounts, we controlled for both the number of hand hygiene opportunities at each hour of a given shift for

${ }^{9}$ However, prior studies have shown that fewer caregiver-patient interactions and fewer hand hygiene opportunities per hour are actually associated with higher hand hygiene compliance rates (WHO, 2009). 
a given caregiver (compliance opportunities per $\mathrm{hr}$ ) and the total number of hand cleansings a given caregiver had performed prior to a given hand cleansing opportunity during a given shift (cumulative hand cleansings; see Table 2, Model 2). In fact, for an additional hour at work, the fitted odds of a caregiver complying with hand hygiene guidelines are estimated to decrease by a factor of 0.87 or $13 \%$ (a surprisingly larger factor than in our original specification) in this more conservative model specification, strongly supporting Hypothesis 1.

\section{$\underline{\text { Work Intensity as a Moderator }}$}

We now turn to a test of our hypothesis that work intensity exacerbates the negative relationship between hours at work and compliance with hand hygiene guidelines (Hypothesis 2). Models 3 and 4 in Table 2 include interactions between hours at work and each of the two work intensity measures described previously (moving average frequency of patient encounters and moving average \% of time in patient rooms). The coefficient estimate associated with each of these interaction terms is negative and statistically significant. ${ }^{10}$ To examine the moderating effects of work intensity, following Preacher, Curran, and Bauer (2006), we plotted the fitted probability of compliance for an average caregiver as a function of hours at work at the $10^{\text {th }}$ and $90^{\text {th }}$ percentiles of the two work intensity moderators described above: moving average frequency of patient encounters (Figure 2a based on Model 3) and moving average \% of time in

\footnotetext{
${ }^{10}$ Note that by our definition, these two measures of work intensity will have extremely high values at the beginning of a shift if the first few episodes are very short. To rule out the possibility that extremely short episodes at the beginning of a shift could distort our findings, we repeated our analyses (Models 3 and 4 in Table 2) but excluded either (a) each caregiver's first hand hygiene opportunity or (b) all hand hygiene opportunities occurring within the first hour of a given caregiver's shift. Our results were robust to the imposition of these data restrictions.
} 
patient rooms (Figure 2b based on Model 4). ${ }^{11}$ Consistent with Hypothesis 2, the interactions depicted in Figure 2 indicate that hours at work have a stronger negative relationship with compliance when caregivers have had more frequent interactions with patients during a shift and when caregivers have spent a larger proportion of their time in patient rooms $(p<.0001$ in simple slope tests for both moderators).

\section{The Effect of Time off between Shifts on Hand Hygiene Compliance}

We next turn to a test of the hypothesis that the more time caregivers take off between work shifts, the more their subsequent hand hygiene compliance improves (Hypothesis 3). Before investigating this hypothesis, however, we removed a subset of problematic observations from our dataset. First, we excluded each caregiver's first shift in our dataset because for the first shift, we do not know when a caregiver's previous shift ended $\left(N_{\text {shifts }}=4,157, N_{\text {hygeine_opportunities }}=\right.$ 119,440). ${ }^{12}$ Also, we are interested in whether time off from work can improve compliance with professional standards by restoring executive function for employees who are active members of the caregiver work force taking typical amounts of time off. Therefore, we focused on recovery benefits of ordinary breaks from work and excluded caregivers who took atypically long breaks between shifts. In healthcare settings, weekly full-time schedules for caregivers typically include (a) five eight-hour shifts or (b) three 12-hour shifts (Stimpfel \& Aiken, 2013). A 108 hour (or 4.5

${ }^{11}$ Because the variable moving average frequency of patient encounters is so highly skewed that its standard deviation is bigger than its mean, we analyzed the $10^{\text {th }}$ and $90^{\text {th }}$ percentiles of this variable. Consistent with this practice, we used the $10^{\text {th }}$ and $90^{\text {th }}$ percentiles of all moderator variables when plotting the fitted probability of compliance.

12 Among the 119,474 hand hygiene opportunities associated with caregivers' first shifts, 2,654 opportunities were associated with 218 caregivers who were observed during just one shift. These caregivers were thus dropped from the analysis entirely when we excluded caregivers' first shifts. 
day) break corresponds to the maximum break length per week that full-time caregivers experience if their work conforms to either of these aforementioned, common schedules. ${ }^{13}$ Thus, our final sample included 214,684 shifts that occurred within 108 hours (or 4.5 days) after the end of a caregiver's previous shift $(\mathrm{N}=11,437,840)$.

To investigate the extent to which time away from work predicted subsequent hand hygiene compliance, for every person and every shift, we calculated the time elapsed in hours since a caregiver's last shift (hours off work). Note that all hand hygiene opportunities that occurred during a given shift followed the same period off and thus the value of hours off work did not vary within a caregiver-shift. In Model 5 in Table 2, we simultaneously examined how the time since the start of a caregiver's current shift and the length of a caregiver's time off since her previous shift relate to compliance at a given hand hygiene opportunity. Model 5 relies on the same specification as Model 2, but Model 5 includes an additional predictor of interest hours off work. Model 5 in Table 2 shows that the coefficient on hours off work is positive and significant, indicating that, as predicted, more time off is associated with higher compliance rates. Specifically, taking an additional half a day off (12 hours) is associated with a 1 percent increase in the odds that a caregiver is compliant when faced with a given hand hygiene opportunity on her subsequent shift. While this effect is fairly small in size, even small increases in hand hygiene are valuable given the significant impact of hand cleanliness on preventing infections (WHO, 2009).

13108 hours are calculated by assuming that a caregiver works three 12 -hour shifts on three consecutive days and takes 4.5 days off. As a robustness check, we confined our analysis to different maximum lengths of breaks ranging from two weeks to two days, and our results remained qualitatively the same (see Electronic Companion Appendix B entitled Robustness Tests for details). 
$\underline{\text { Hand Hygiene Compliance at the End of a Caregiver's Previous Shift as a Moderator of Time off }}$ $\underline{\text { between Shifts }}$

We now turn to the hypothesis that caregivers benefit more from time off the lower their hand hygiene compliance had fallen at the end of their previous shift (Hypothesis 4). As described above, for every shift, we calculated the average compliance rate associated with the final hour of a caregiver's preceding shift (“compliance in the final hour of the preceding shift"). Model 6 in Table 2 includes the interaction between hours off work and compliance in the final hour of the preceding shift and shows a significant and negative coefficient on this interaction term. Again using the Preacher et al., (2006) approach, we depicted the fitted probability of compliance as a function of hours off work at the $10^{\text {th }}$ and $90^{\text {th }}$ percentiles of the variable compliance in the final hour of the preceding shift, based on Model 6 in Table 2. As depicted in Figure 3 and consistent with Hypothesis 4, time off between shifts is associated with a significantly greater boost in caregivers' hand hygiene compliance upon their return to work when caregivers exhibited lower hand hygiene compliance at the end of their previous shift $(p<$ .0001 in a simple slope test).

Spillover Effects of Accumulated Work Demands

So far we have presented evidence suggesting that work demands take an immediate toll on compliance. We also hypothesized that greater accumulated exposure to work demands would create spillover effects, harming compliance on subsequent work shifts (Hypothesis 5). As described above, for every shift, we calculated the total number of hours that a caregiver spent at work in the seven days prior to the start of the shift in question ("total hours at work in the past week"). As shown in Model 7 (Table 2), the interaction between hours at work and total hours at work in the past week is significant and negative. Again using the approach of Preacher et al. 
(2006) to examine the interaction effect, we depicted the fitted probability of compliance as a function of hours at work at the $10^{\text {th }}$ and $90^{\text {th }}$ percentiles of the variable total hours at work in the past week, based on Model 7 in Table 2. Figure 4a indicated that the more total hours a caregiver had worked in the past week, the faster her compliance decreased during a given shift $(p<.01$ in a simple slope test).

Furthermore, we predicted that accumulated work demands from recent shifts would affect how much caregivers benefit from time off between shifts. Model 8 in Table 2 indicates that the coefficient on the interaction term between hours off work and total hours at work in the past week is positive and significant. ${ }^{14}$ As illustrated in Figure $4 \mathrm{~b}$, this interaction suggests that the more hours a caregiver worked in the previous week, the stronger the positive association between a longer break between shifts and a caregiver's hand hygiene compliance upon her return to work $(p=.01$ in a simple slope test).

\section{Discussion}

Although past research has demonstrated that, in general, high work demands are related to decreased compliance with safety guidelines, there has been no research to date suggesting that the impact of work demands may accumulate very quickly - for example, over the course of a typical, 12-hour shift. Using three years of electronic records on hand hygiene compliance in a population including thousands of healthcare workers, we show that hand hygiene compliance rates decrease over the course of a normal work shift - an effect that is accentuated when

14 The correlation coefficient between hours off work and total hours at work in the past week is - 0.14, suggesting that the significant interaction between these variables is unlikely to be the spurious outcome of multicollinearity. 
caregivers engage in more intense work. ${ }^{15}$ Further, we find that more time off between shifts appears to serve a restorative purpose as it is associated with higher hand hygiene compliance on a caregiver's subsequent shift. In particular, more time off is associated with greater improvements in compliance rates when caregivers exhibited lower hygiene compliance rates at the end of their previous shift. In addition, we show that the longer a caregiver worked in the past week, the faster her compliance declines over the course of a shift and the more her compliance improves from more time off between shifts.

We expect that the effects documented here of accumulated time at work, work intensity, and time off from work are likely relevant to many forms of routine compliance in organizations. Future research exploring the relationship between work demands and compliance in a broader set of contexts (e.g., applying this idea to ethics standards in banking, safe driving behaviors in trucking, or safety standards in manufacturing) would be valuable. However, there may be important boundary conditions. For example, it would be valuable to investigate whether time on and off work also affects compliance with standards that are not part of day-to-day routines (e.g., rules designed for emergencies). Also, it would be useful to learn whether our findings apply to employees for whom work demands increase job satisfaction and intrinsic motivation (e.g., LePine, Podsakoff, \& LePine, 2005).

${ }^{15}$ It is unlikely that our findings can be simply explained by caregivers engaging in an optimal level of hand hygiene. First, ample evidence has shown that increased compliance is associated with reduced infection rates in healthcare settings (WHO, 2009; CDC, 2002), suggesting that caregivers are not optimizing their hand hygiene compliance. Second, based on conversations with nurses and according to descriptions of nursing jobs, there is no evidence that the nature of patient care changes across caregiver shifts in a systematic way such that caregivers' hand hygiene needs decrease over time. Also, we did not find that the duration of patient room visits changed significantly over the course of a shift in our data set. 
One limitation of our data is that we cannot measure individuals' psychological states or perceptions. It would be valuable for future research to more directly explore a mechanism responsible for our findings. For example, future research could employ the experience-sampling method to measure employees' perceived workload and subjective fatigue at various points in time at work, which could be matched with records of compliance with professional standards.

The results of this paper point to a previously unexplored and high cost of intra-shift workplace fatigue - an increase in deviations from professional guidelines. These deviations pose a threat to the well-being of organizations, employees, and clients (in this case, patients), because such violations can reduce the quality of products produced and services provided as well as creating an unsafe work environment. In the context of hand hygiene, the regressionestimated reduction in compliance over the course of a normal, 12-hour shift of 8.5 percentage points (based on Model 1 in Table 2) would be expected to produce an additional 33 infections per 1,000 patients at an estimated cost of nearly $\$ 25$ billion annually across the 5,723 registered hospitals in the United States (Scott, 2009). ${ }^{16}$

In conclusion, the findings reported here suggest that demanding work environments can produce negative consequences far more rapidly than prior work exploring the effects of high job demands has recognized (e.g., Bakker \& Demerouti, 2007; Demerouti et al., 2001). In other words, a day in the saddle can indeed take its toll where the immediate and continuous job demands result in a gradual reduction in compliance with professional standards over the course of day. Clearly, future research should investigate how to reduce these harmful effects of work demands on routine compliance.

\footnotetext{
${ }^{16}$ See Appendix F for our calculation.
} 


\section{Bibliography}

Bakker, A. B., \& Demerouti, E. (2007). The job demands-resources model: State of the art. Journal of Managerial Psychology, 22(3), 309-328

Bakker, A. B., Demerouti, E., de Boer, E., \& Schaufeli, W. B. (2003). Job demands and job resources as predictors of absence duration and frequency. Journal of Vocational Behavior, 62(2), 341-356. doi:10.1016/S0001-8791(02)00030-1

Bakker, A. B., Schaufeli, W. B., Sixma, H. J., Bosveld, W., \& Van Dierendonck, D. (2000). Patient demands, lack of reciprocity, and burnout: A five-year longitudinal study among general practitioners. Journal of Organizational Behavior, 21(4), 425-441

Battisto, D., Pak, R., Vander Wood, M. A., \& Pilcher, J. J. (2009). Using a task analysis to describe nursing work in acute care patient environments. Journal of Nursing Administration, 39(12), 537-547. doi: 10.1097/NNA.0b013e3181c1806d

Baumeister, R. F., Bratslavsky, E., Muraven, M., \& Tice, D. M. (1998). Ego depletion: Is the active self a limited resource? Journal of Personality and Social Psychology, 74(5), 1252-1265. doi: 10.1037/0022-3514.74.5.1252

Binnewies, C., Sonnentag, S., \&Mojza, E. J. (2010). Recovery during the weekend and fluctuations in weekly job performance: A week-level study examining intra-individual relationships. Journal of Occupational and Organizational Psychology, 83(2), 419-441. doi:10.1348/096317909x418049

Campion, M. A. (1988). Interdisciplinary approaches to job design - a constructive replication with extensions. Journal of Applied Psychology, 73(3), 467-481. doi:10.1037//00219010.73.3.467 
Centers for Disease Control and Prevention. (2002). Guideline for hand hygiene in health-care settings: Recommendations of the healthcare infection control practices advisory committee and the HICPAC/SHEA/APIC/IDSA hand hygiene task force. Morbidity and Mortality Weekly Report, 51, RR-16

Crawford, E. R., LePine, J. A., \& Rich, B. L. (2010). Linking job demands and resources to employee engagement and burnout: A theoretical extension and meta-analytic test. Journal of Applied Psychology, 95(5), 834-848. doi:10.1037/A0019364

Danziger, S., Levav, J., \&Avnaim-Pesso, L. (2011). Extraneous factors in judicial decisions. Proceedings of the National Academy of Sciences of the United States of America, 108(17), 6889-6892. doi:10.1073/pnas.1018033108

DeLucia, P. R., Ott, T. E., \& Palmieri, P. A. (2009). Performance in nursing. In F. T. Durso (Ed.), Reviews of human factors and ergonomics (Vol. 5, pp. 1-40): Human Factors and Ergonomics Society.

Demerouti, E., Bakker, A. B., Nachreiner, F., \& Schaufeli, W. B. (2001). The job demandsresources model of burnout. Journal of Applied Psychology, 86(3), 499-512. doi:10.1037//0021-9010.86.3.499

Dollard, M. F., \& McTernan, W. (2011). Psychosocial safety climate: a multilevel theory of work stress in the health and community service sector. Epidemiology and Psychiatric Sciences, 20(4), 287-293. doi:10.1017/S2045796011000588

Erasmus, V., Brouwer, W., van Beeck, E. F., Oenema, A., Daha, T. J., Richardus, J. H., . . Brug, J. (2009). A qualitative exploration of reasons for poor hand hygiene among hospital workers: Lack of positive role models and of convincing evidence that hand 
hygiene prevents cross-infection. Infection Control and Hospital Epidemiology, 30(5), 415-419. doi:10.1086/596773

Ferrara, M., \& De Gennaro, L. (2001). How much sleep do we need? Sleep Medicine Reviews, 5(2), 155-179. doi:10.1053/smrv.2000.0138

Fritz, C., \& Sonnentag, S. (2005). Recovery, health, and job performance: Effects of weekend experiences. Journal of Occupational Health Psychology, 10(3), 187-199. doi:10.1037/1076-8998.10.3.187

Fritz, C., \& Sonnentag, S. (2006). Recovery, well-being, and performance-related outcomes: The role of workload and vacation experiences. Journal of Applied Psychology, 91(4), 936945. doi:10.1037/0021-9010.91.4.936

Gailliot, M. T., \& Baumeister, R. F. (2007). The physiology of willpower: Linking blood glucose to self-control. Personality and Social Psychology Review, 11(4), 303-327. doi: $10.1177 / 1088868307303030$

Gailliot, M. T., Baumeister, R. F., DeWall, C. N., Maner, J. K., Plant, E. A., Tice, D. M., .. . Schmeichel, B. J. (2007). Self-control relies on glucose as a limited energy source: Willpower is more than a metaphor. Journal of Personality and Social Psychology, 92(2), 325-336. doi:10.1037/0022-3514.92.2.325

Hagger, M. S., Wood, C., Stiff, C., \& Chatzisarantis, N. L. D. (2010). Ego depletion and the strength model of self-control: A meta-analysis. Psychological Bulletin, 136(4), 495-525. doi:10.1037/A0019486

Hansez, I., \& Chmiel, N. (2010). Safety behavior: job demands, job resources, and perceived management commitment to safety. Journal of Occupational Health Psychology, 15(3), 267-278. doi: 10.1037/A0019528 
Haynes, A. B., Weiser, T. G., Berry, W. R., Lipsitz, S. R., Breizat, A. H. S., Dellinger, E. P., . . for the Safe Surgery Saves Lives Study Group. (2009). A surgical safety checklist to reduce morbidity and mortality in a global population. New England Journal of Medicine, 360(5), 491-499. doi:10.1056/Nejmsa0810119

Hockey, G. R. J. (1993). Cognitive-energetical control mechanisms in the management of work demands and psychological health. In A. D. Baddeley \& L. Weiskrantz (Eds.), Attention, selection, awareness and control: a tribute to Donald Broadbent (pp. 328-345). Oxford, England: Oxford University Press

Hockey, G. R. J. (1997). Compensatory control in the regulation of human performance under stress and high workload: A cognitive-energetical framework. Biological Psychology, 45(1-3), 73-93

Hofmann, D. A., \& Frese, M. (2011). Errors in organizations. New York, NY: Routledge

Hofmann, D. A., \& Stetzer, A. (1996). A cross-level investigation of factors influencing unsafe behaviors and accidents. Personnel Psychology, 49(2), 307-339. doi:10.1111/j.17446570.1996.tb01802.x

Houtman, I. L., \& Kompier, M. A. (1995). Risk factors and occupational risk groups for work stress in the Netherlands. In S. L. Sauter \& L. R. Murphy (Eds.), Organizational risk factors for job stress (Vol. xii, pp. 209-225). Washington, DC: American Psychological Association

Hugonnet, S., \& Pittet, D. (2000). Hand hygiene-beliefs or science? Clinical microbiology and infection, 6(7), 348-354 
Joint Commission Center for Transforming Healthcare. (2013). Hand hygiene project and the targeted solutions tool. Retrieved August 4, 2013, from http://www.centerfortransforminghealthcare.org/faq.aspx?CategoryId=49\#1111

Karasek, R., \& Theorell, T. (1990). Healthy work: Stress productivity and the reconstruction of working life. New York, NY: Basic Books

Kc, D. S., \& Terwiesch, C. (2009). Impact of workload on service time and patient safety: an econometric analysis of hospital operations. Management Science, 55(9), 1486-1498. doi: DOI $10.1287 / \mathrm{mnsc} .1090 .1037$

Kouchaki, M., \& Smith, I. H. (2014). The morning morality effect: The influence of time of day on unethical behavior. Psychological science, 25(1), 95-102

Lepine, J. A., Podsakoff, N. P., \& Lepine, M. A. (2005). A meta-analytic test of the challenge stressor-hindrance stressor framework: an explanation for inconsistent relationships among stressors and performance. Academy of Management Journal, 48(5), 764-775

Linder, J. A., Doctor, J. N., Friedberg, M., Nieva, H. R., Birks, C., Meeker, D., \& Fox, C. (2013). Antibiotic prescribing for acute respiratory infections increases as the clinic session wears on. Poster presented at the 2013 Academy Health Annual Research Meeting, Baltimore, MD

Nahrgang, J. D., Morgeson, F. P., \& Hofmann, D. A. (2011). Safety at work: A meta-analytic investigation of the link between job demands, job resources, burnout, engagement, and safety outcomes. Journal of Applied Psychology, 96(1), 71-94. doi:10.1037/A0021484

Page, A. E. (2004). Keeping patients safe: Transforming the work environment of nurses. Washington, DC: National Academies Press 
Preacher, K. J., Curran, P. J., \& Bauer, D. J. (2006). Computational tools for probing interactions in multiple linear regression, multilevel modeling, and latent curve analysis. Journal of Educational and Behavioral Statistics, 31(4), 437-448. doi:10.3102/10769986031004437

Reason, J. T. (1995). Understanding adverse events: human factors. Quality in Health Care, 4, 80-89

Reason, J.T., Parker, D., \& Lawton, R. (1998). Organizational controls and safety: The varieties of rule-related behaviour. Journal of Occupational and Organizational Psychology, 71, 289-304

Rogers, A. E., Hwang, W. T., \& Scott, L. D. (2004). The effects of work breaks on staff nurse performance. Journal of Nursing Administration, 34(11), 512-519. doi:10.1097/00005110-200411000-00007

Schaufeli, W. B., Bakker, A. B., \& Van Rhenen, W. (2009). How changes in job demands and resources predict burnout, work engagement, and sickness absenteeism. Journal of Organizational Behavior, 30(7), 893-917. doi:10.1002/Job.595

Schmidt, A. M., \&DeShon, R. P. (2007). What to do? The effects of discrepancies, incentives, and time on dynamic goal prioritization. Journal of Applied Psychology, 92(4), 928-941. doi:10.1037/0021-9010.92.4.928

Scott, R.D. (2009). The direct medical costs of healthcare-associated infections in U.S. hospitals and the benefits of prevention. Available at: http://www.cdc.gov/ncidod/dhqp/pdf/Scott_CostPaper.pdf. Accessed August 2, 2013

See, J. E., Howe, S. R., Warm, J. S., \& Dember, W. N. (1995). Meta-analysis of the sensitivity decrement in vigilance. Psychological Bulletin, 117(2), 230 
Sonnentag, S., Binnewies, C., \& Mojza, E. J. (2008). "Did you have a nice evening?" A daylevel study on recovery experiences, sleep, and affect. Journal of Applied Psychology, 93(3), 674-684. doi:10.1037/0021-9010.93.3.674

Sonnentag, S., Kuttler, I., \& Fritz, C. (2010). Job stressors, emotional exhaustion, and need for recovery: A multi-source study on the benefits of psychological detachment. Journal of Vocational Behavior, 76(3), 355-365. doi:10.1016/j.jvb.2009.06.005

Staats, B. R., \& Gino, F. (2012). Specialization and Variety in Repetitive Tasks: Evidence from a Japanese Bank. Management Science, 58(6), 1141-1159. doi:10.1287/mnsc.1110.1482

Steed, C., Kelly, J. W., Blackhurst, D., Boeker, S., Diller, T., Alper, P., \& Larson, E. (2011). Hospital hand hygiene opportunities: Where and when (HOW2)? The HOW2 Benchmark Study. American Journal of Infection Control, 39(1), 19-26. doi: 10.1016/j.ajic.2010.10.007

Stimpfel, A. W., \& Aiken, L. H. (2013). Hospital staff nurses' shift length associated with safety and quality of care. Journal of Nursing Care Quality, 28(2), 122-129

Stimpfel, A. W., Sloane, D. M., \& Aiken, L. H. (2012). The longer the shifts for hospital nurses, the higher the levels of burnout and patient dissatisfaction. Health Affairs, 31(11), 25012509. doi:10.1377/hlthaff.2011.1377

Tice, D. M., Baumeister, R. F., Shmueli, D., \& Muraven, M. (2007). Restoring the self: Positive affect helps improve self-regulation following ego depletion. Journal of Experimental Social Psychology, 43(3), 379-384. doi:10.1016/j.jesp.2006.05.007

Trougakos, J. P., Beal, D. J., Green, S. G., \& Weiss, H. M. (2008). Making the break count: An episodic examination of recovery activities, emotional experiences, and positive affective displays. Academy of Management Journal, 51(1), 131-146 
Turner, N., Chmiel, N., Hershcovis, M. S., \& Walls, M. (2010). Life on the line: Job demands, perceived co-worker support for safety, and hazardous work events. Journal of Occupational Health Psychology, 15(4), 482-493. doi:10.1037/A0021004

Tyler, J. M., \& Burns, K. C. (2008). After depletion: The replenishment of the self's regulatory resources. Self and Identity, 7(3), 305-321. doi:10.1080/15298860701799997

Westman, M., \& Eden, D. (1997). Effects of a respite from work on burnout: Vacation relief and fade-out. Journal of Applied Psychology, 82(4), 516-527. doi:10.1037//00219010.82 .4 .516

World Health Organization. (2009). WHO guidelines on hand hygiene in healthcare. Geneva, Switzerland: World Health Organization Press 
Table 1. Means, standard deviations, and correlations for all variables included in our analyses $(N=13,773,022)$

\begin{tabular}{|c|c|c|c|c|c|c|c|c|c|c|c|c|c|c|c|c|c|c|c|}
\hline & $\sum_{\Sigma}^{\tilde{E}}$ & 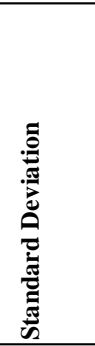 & 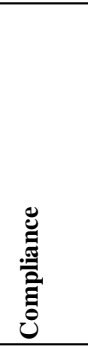 & 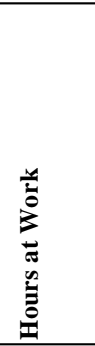 & 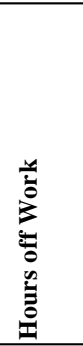 & 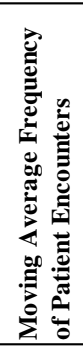 & 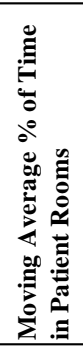 & 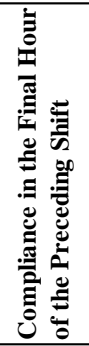 & 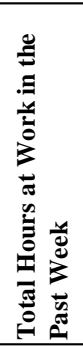 & 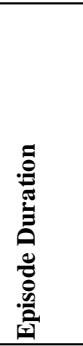 & 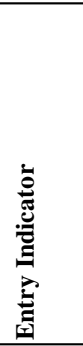 & 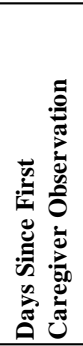 & 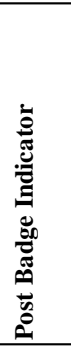 & 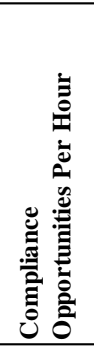 & 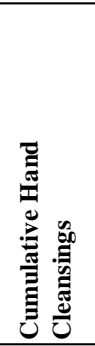 & 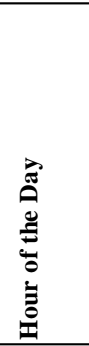 & 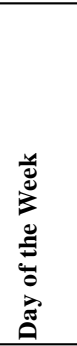 & 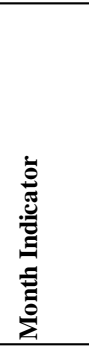 & 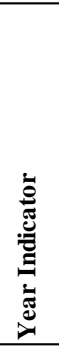 \\
\hline Compliance & 0.38 & 0.49 & 1.00 & & & & & & & & & & & & & & & & \\
\hline Hours at Work & 5.02 & 3.57 & $-0.04^{*}$ & 1.00 & & & & & & & & & & & & & & & \\
\hline Hours off Work & 67.78 & 182.95 & $-0.02 *$ & $-0.01^{*}$ & 1.00 & & & & & & & & & & & & & & \\
\hline Moving Average Frequency of Patient Encounters & 6.44 & 9.28 & $-0.03^{*}$ & $-0.27 *$ & $0.01 *$ & 1.00 & & & & & & & & & & & & & \\
\hline Moving Average \% of Time in Patient Rooms & 0.37 & 0.21 & $0.08^{*}$ & $-0.30 *$ & $0.00^{*}$ & $0.44 *$ & 1.00 & & & & & & & & & & & & \\
\hline Compliance in the Final Hour of the Preceding Shift & 0.35 & 0.32 & $0.42 *$ & $0.00 *$ & $-0.05^{*}$ & $-0.05^{*}$ & $0.07 *$ & 1.00 & & & & & & & & & & & \\
\hline Total Hours at Work in the Past Week & 24.49 & 12.94 & $0.05^{*}$ & $0.04 *$ & $-0.29 *$ & $0.00^{*}$ & $0.04 *$ & $0.08^{*}$ & 1.00 & & & & & & & & & & \\
\hline Episode Duration & 0.09 & 0.13 & $0.04 *$ & $0.01 *$ & $0.00 *$ & $-0.13^{*}$ & $0.08^{*}$ & $0.04 *$ & $-0.01 *$ & 1.00 & & & & & & & & & \\
\hline Entry Indicator & 0.50 & 0.50 & $-0.10^{*}$ & $-0.01 *$ & -0.00 & $-0.09 *$ & $-0.14^{*}$ & 0.00 & 0.00 & 0.00 & 1.00 & & & & & & & & \\
\hline Days Since First Caregiver Obs & 200.01 & 171.62 & $0.09 *$ & $0.01 *$ & $0.02 *$ & $-0.02 *$ & -0.00 & $0.11 *$ & $0.01 *$ & $0.03^{*}$ & 0.00 & 1.00 & & & & & & & \\
\hline Post Badge Indicator & 0.98 & 0.12 & $0.05^{*}$ & $0.01^{*}$ & $0.00^{*}$ & $0.00 *$ & $0.00 *$ & $0.06^{*}$ & $0.03 *$ & $-0.01 *$ & 0.00 & $0.11^{*}$ & 1.00 & & & & & & \\
\hline Compliance Opportunities Per Hour & 11.70 & 9.05 & $-0.10^{*}$ & $-0.11^{*}$ & $0.00^{*}$ & $0.32^{*}$ & $0.20 *$ & $-0.13^{*}$ & $0.05^{*}$ & $-0.23^{*}$ & $0.00^{*}$ & $-0.05^{*}$ & $0.00^{*}$ & 1.00 & & & & & \\
\hline Cumulative Hand Cleansings & 16.42 & 19.66 & $0.27 *$ & $0.49 *$ & $-0.03^{*}$ & $-0.06^{*}$ & $0.03 *$ & $0.40^{*}$ & $0.13^{*}$ & $-0.04 *$ & $-0.01^{*}$ & $0.07 *$ & $0.05^{*}$ & $0.07 *$ & 1.00 & & & & \\
\hline Hour of the Day & 11.94 & 6.25 & $-0.01^{*}$ & $-0.09 *$ & 0.00 & $0.00^{*}$ & $0.05^{*}$ & $0.00^{*}$ & $0.01 *$ & $0.00 *$ & $-0.01 *$ & $-0.01 *$ & $0.00 *$ & $0.00^{*}$ & $-0.02 *$ & 1.00 & & & \\
\hline Day of the Week & 3.89 & 1.95 & 0.00 & $0.01^{*}$ & $-0.03^{*}$ & $0.00^{*}$ & $0.01 *$ & $0.01 *$ & $-0.06^{*}$ & 0.00 & 0.00 & $0.00^{*}$ & $0.01^{*}$ & $0.00^{*}$ & $0.01^{*}$ & $-0.02 *$ & 1.00 & & \\
\hline Month Indicator & 6.57 & 3.56 & $0.01 *$ & $-0.00^{*}$ & $0.00 *$ & $-0.02 *$ & $-0.01^{*}$ & $0.02 *$ & $-0.02 *$ & $0.02 *$ & 0.00 & $-0.02^{*}$ & $0.05^{*}$ & $-0.05^{*}$ & $0.00^{*}$ & $0.00^{*}$ & $0.01 *$ & 1.00 & \\
\hline Year Indicator & 2011.94 & 0.63 & $0.23 *$ & $-0.02 *$ & $-0.02 *$ & $-0.06^{*}$ & $0.00 *$ & $0.31 *$ & $0.04 *$ & $0.02 *$ & 0.00 & $0.15^{*}$ & $0.14^{*}$ & $-0.14^{*}$ & $0.20^{*}$ & 0.00 & $0.00^{*}$ & $-0.43^{*}$ & 1.00 \\
\hline
\end{tabular}

\section{* p-value $<.05$}

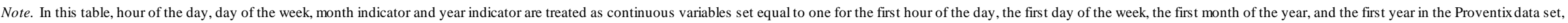
respectively. Our regression models include dummy indicators for these variables as described in Control Variables section. 
Table 2. Hand hygiene compliance is predicted using three-level random intercept logistic regressions as a function of various characteristics of a given hand hygiene opportunity. Models 1-4 and 7 examine the effects of hours elapsed since the beginning of a caregiver's shift on compliance. Models 5, 6, and 8 also further estimate the effects of the time off between shifts on hand hygiene compliance.

\begin{tabular}{|c|c|c|c|c|c|c|c|c|}
\hline & Model 1 & Model 2 & Model 3 & Model 4 & Model $5^{\mathrm{a}}$ & Model $6^{\mathrm{a}}$ & Model $7^{\mathrm{b}}$ & Model $8^{\mathrm{c}}$ \\
\hline \multicolumn{9}{|l|}{ Primary Predictors } \\
\hline Hours at work & $\begin{array}{l}-0.0316^{* * *} \\
(0.0032)\end{array}$ & $\begin{array}{l}-0.1347 * * * \\
(0.0061)\end{array}$ & $\begin{array}{l}-0.2367 * * * \\
(0.0189)\end{array}$ & $\begin{array}{l}-0.1518 * * * \\
(0.0078)\end{array}$ & $\begin{array}{l}-0.1350 * * * \\
(0.0063)\end{array}$ & $\begin{array}{l}-0.1199 * * * \\
(0.0050)\end{array}$ & $\begin{array}{l}-0.1347 * * * \\
(0.0059)\end{array}$ & $\begin{array}{l}-0.1343 * * * \\
(0.0062)\end{array}$ \\
\hline Hours off work & & & & & $\begin{array}{l}0.0007 * * * \\
(0.0001)\end{array}$ & $\begin{array}{l}0.0011^{* * * *} \\
(0.0001)\end{array}$ & & $\begin{array}{l}0.0008 * * * \\
(0.0001)\end{array}$ \\
\hline \multicolumn{9}{|l|}{ Moderators } \\
\hline $\begin{array}{l}\text { Moving average frequency of patient } \\
\text { encounters } \\
\text { (Hours at work)*(Moving average } \\
\text { frequency of patient encounters) }\end{array}$ & & & $\begin{array}{l}-0.1297 * * * \\
(0.0164) \\
-0.0247 * * * \\
(0.0033)\end{array}$ & & & & & \\
\hline $\begin{array}{l}\text { Moving average } \% \text { of time in patient } \\
\text { rooms }\end{array}$ & & & & $\begin{array}{l}-0.6500 * * * \\
(0.0940)\end{array}$ & & & & \\
\hline $\begin{array}{l}\text { (Hours at work)*(Moving average } \% \text { of } \\
\text { time in patient rooms) }\end{array}$ & & & & $\begin{array}{l}-0.1751^{* * * *} \\
(0.0207)\end{array}$ & & & & \\
\hline $\begin{array}{l}\text { Compliance in the final hour of the } \\
\text { preceding shift }\end{array}$ & & & & & & $\begin{array}{l}1.0647 * * * \\
(0.0405)\end{array}$ & & \\
\hline $\begin{array}{l}\text { (Hours off work })^{*}(\text { Compliance in the } \\
\text { final hour of the preceding shift) }\end{array}$ & & & & & & $\begin{array}{l}-0.0025 * * * \\
(0.0003)\end{array}$ & & \\
\hline Total hours at work in the past week & & & & & & & $\begin{array}{l}0.0010^{* *} \\
(0.0004)\end{array}$ & $\begin{array}{l}0.0014 * * * \\
(0.0004)\end{array}$ \\
\hline $\begin{array}{l}\text { (Hours at work)*(Total hours at work in } \\
\text { the past week) }\end{array}$ & & & & & & & $\begin{array}{l}-0.0008 * * * \\
(0.0001)\end{array}$ & \\
\hline $\begin{array}{l}\text { (Hours off work)*(Total hours at work in } \\
\text { the past week) }\end{array}$ & & & & & & & & $\begin{array}{l}1.8 \mathrm{e}-05^{* *} \\
(6.6 \mathrm{e}-06)\end{array}$ \\
\hline \multicolumn{9}{|l|}{ Controls Included to Address } \\
\hline Compliance oppprtunities per hr & & $\begin{array}{l}-0.0198 * * * \\
(0.0026)\end{array}$ & $\begin{array}{l}-0.0063 * \\
(0.0029)\end{array}$ & $\begin{array}{l}-0.0181^{* * *} \\
(0.0026)\end{array}$ & $\begin{array}{l}-0.0182 * * * \\
(0.0027)\end{array}$ & $\begin{array}{l}-0.0167 * * * \\
(0.0025)\end{array}$ & $\begin{array}{l}-0.0188^{* * *} \\
(0.0026)\end{array}$ & $\begin{array}{l}-0.0181 * * * \\
(0.0027)\end{array}$ \\
\hline Cumulative hand cleansings & & $\begin{array}{l}0.0309 * * * \\
(0.0019)\end{array}$ & $\begin{array}{l}0.0422 * * * \\
(0.0020)\end{array}$ & $\begin{array}{l}0.0339 * * * \\
(0.0018)\end{array}$ & $\begin{array}{l}0.0303 * * * \\
(0.0019)\end{array}$ & $\begin{array}{l}0.0254 * * * \\
(0.0017)\end{array}$ & $\begin{array}{l}0.0308 * * * \\
(0.0019)\end{array}$ & $\begin{array}{l}0.0299 * * * \\
(0.0019)\end{array}$ \\
\hline
\end{tabular}

Control variables include duration of a room visit, room entry indicator, days since first caregiver observation, and post-monitoring indicator, as well as fixed effects for hour of the day, day of the week, month, and year.

\begin{tabular}{|c|c|c|c|c|c|c|c|c|}
\hline Observations & $13,773,022$ & $13,773,022$ & $13,773,022$ & $13,773,022$ & $11,437,840$ & $11,437,840$ & $13,311,802$ & $11,115,720$ \\
\hline Number of Caregivers & 4,157 & 4,157 & 4,157 & 4,157 & 3,771 & 3,771 & 3,843 & 3,617 \\
\hline
\end{tabular}

${ }^{*},{ }^{* *}$, and ${ }^{* * *}$ denote significance at the $5 \%, 1 \%$, and $0.1 \%$ levels, respectively.

Note: ${ }^{a}$ Sample included all shifts except a worker's first shift or shifts that followed $>=108$ hours off from work.

${ }^{\mathrm{b}}$ Sample included all shifts except those that occurred within 7 days of a worker's first shift

${ }^{\mathrm{c}}$ Sample included all shifts except those that: (a) occurred within 7 days of a worker's first shift or (b) followed $>=108$ hours off from work 
Figure 1. A plot of the relationship between the elapsed hours since a caregiver's shift began and the average rate of hand hygiene compliance among caregivers.

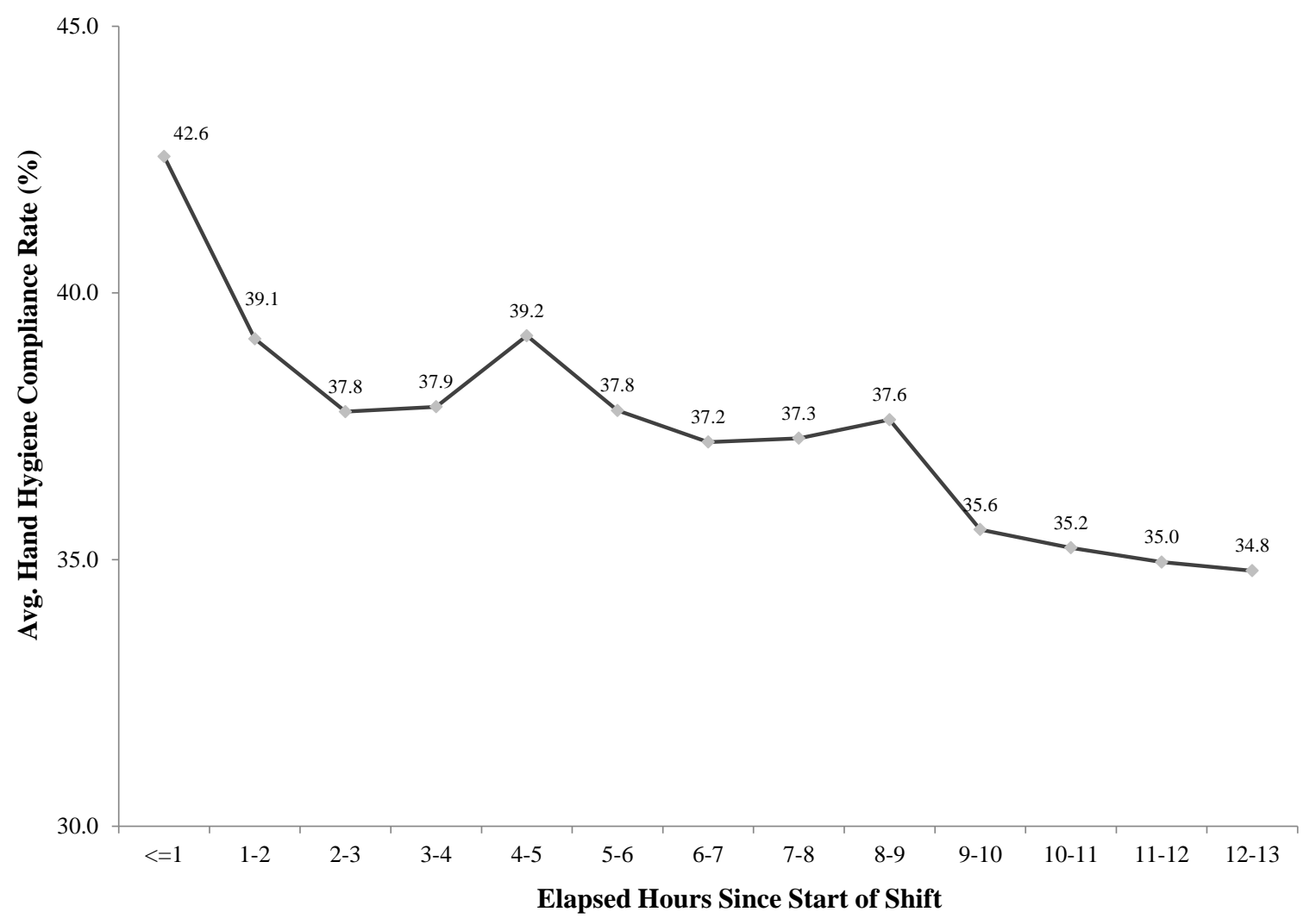

Figure 2. Plots of the fitted probability of compliance as a function of the interaction between the elapsed hours since the start of a caregiver's shift and work intensity measured as (a) the moving average frequency of patient encounters a caregiver has experienced up to a given hand hygiene opportunity (Panel A; Model 3, Table 2) and (b) a caregiver's moving average \% of time in patient rooms up to a given hand hygiene opportunity (Panel B; Model 4, Table 2). ${ }^{17}$

${ }^{17}$ In all of our fitted models (Figures 2-4), our continuous control variables were assigned their mean value while categorical covariates (i.e. our room entry indicator variable, our post-monitoring indicator variable, and fixed effects (for year, month, day of the week, and hour of the day)) were assigned the value of the omitted reference group. 


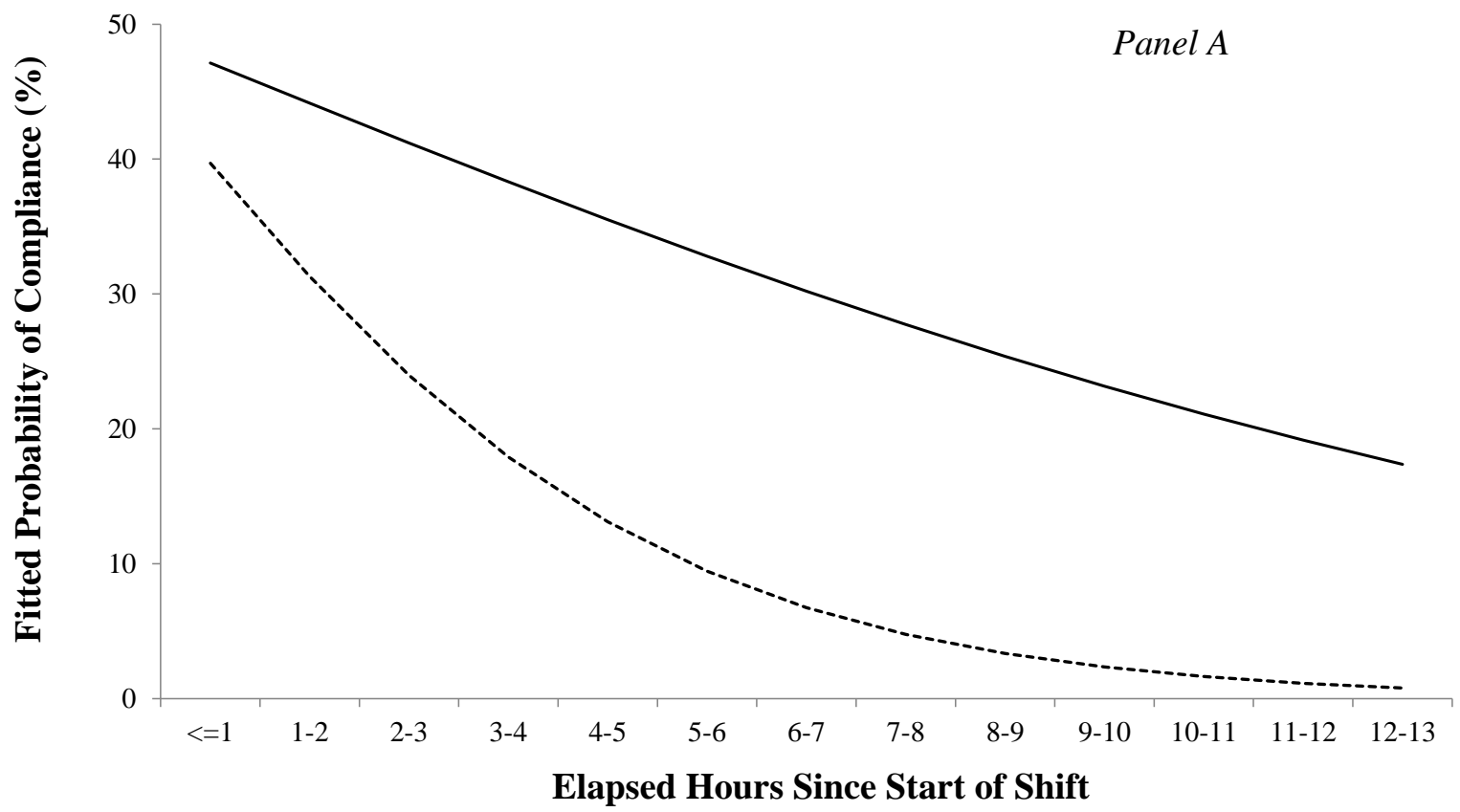

-10th percentile of "moving average frequency of patient encounters" (=1.74 encounters $/ \mathrm{hr})$
---.90 th percentile of "moving average frequency of patient encounters" (=11.76 encounters $/ \mathrm{hr}$ )

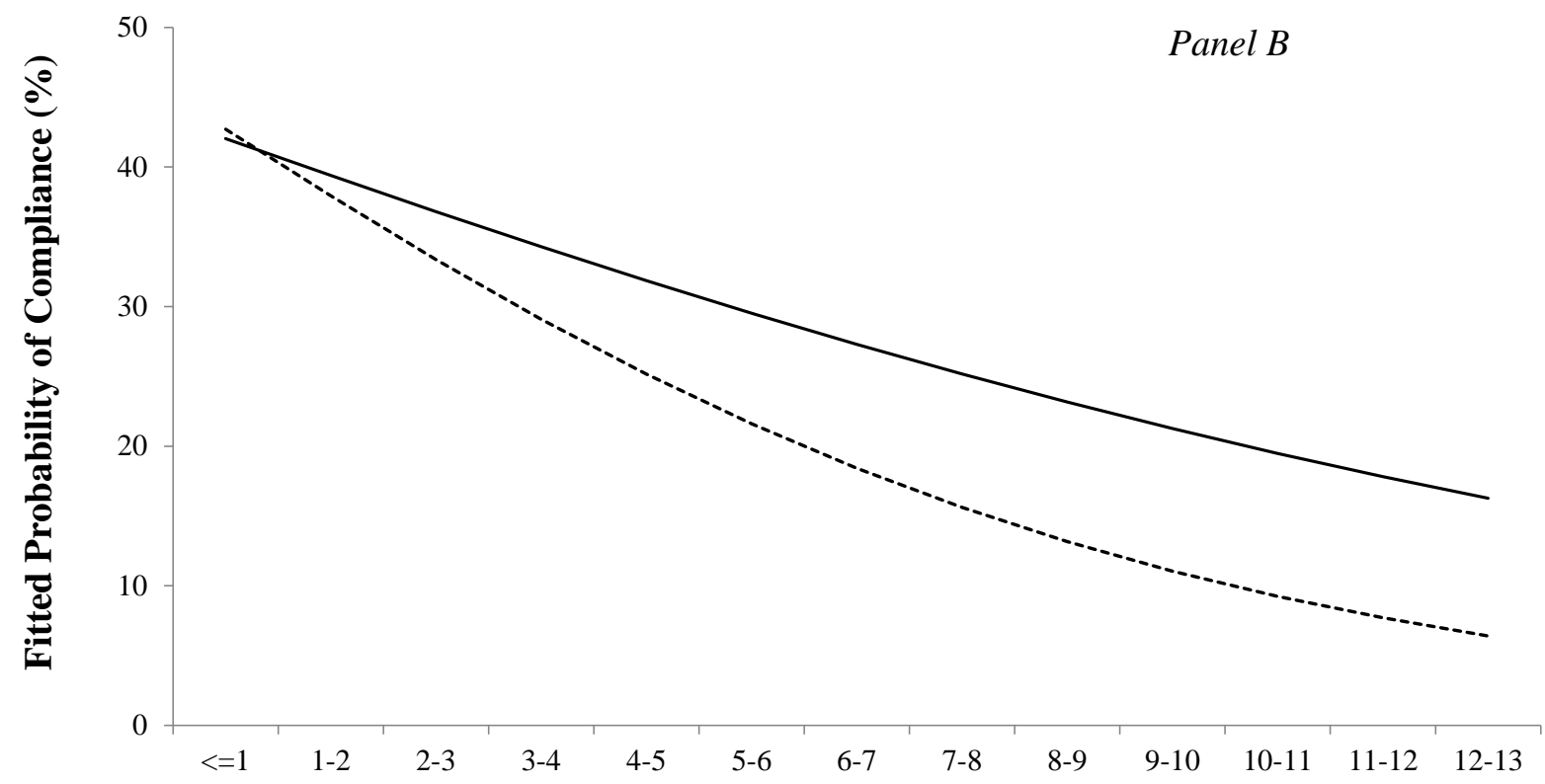

Elapsed Hours Since Start of Shift

10 th percentile of "moving average \% of time in patient rooms" (=13\%)

---.90th percentile of "moving average \% of time in patient rooms" (=64\%) 
Figure 3. Plot of fitted probability of compliance as a function of the interaction between the elapsed hours since a caregiver's previous shift and that caregiver's compliance rate at the end of her previous shift. This plot depicts the moderating effect of the compliance in the final hour of the preceding shift (plotted at the $10^{\text {th }}$ and $90^{\text {th }}$ percentiles) on time off. Compliance rates are fitted based on Model 6 in Table 2.

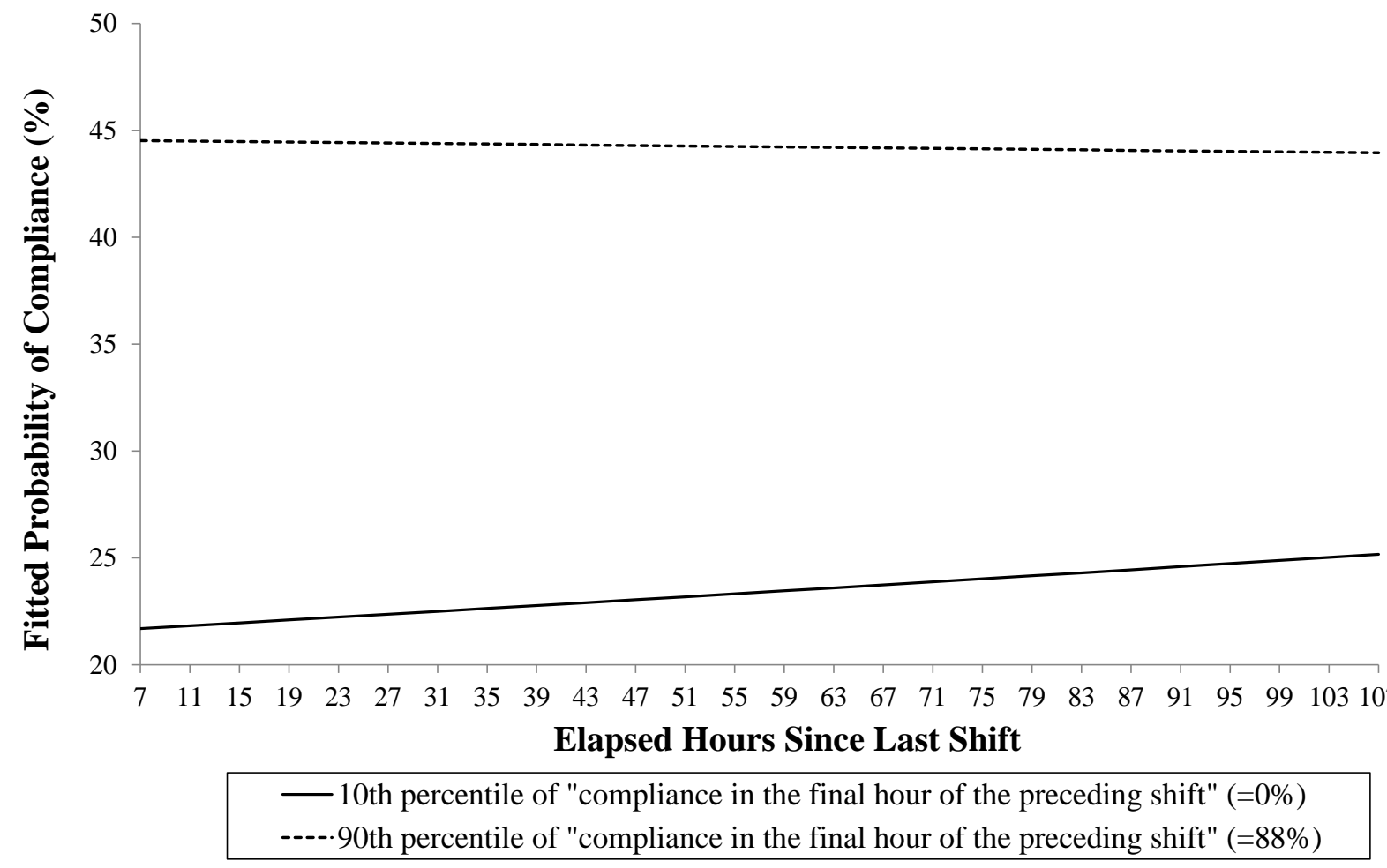


Figure 4. Plots of the fitted probability of compliance as a function of the elapsed hours since the start of a caregiver's shift (Panel A: Model 7 in Table 2) and the elapsed hours since a caregiver's previous shift (Panel B: Model 8 in Table 2). Both plots depict the moderating effect of the total hours at work in the past week (plotted at its $10^{\text {th }}$ and $90^{\text {th }}$ percentiles).
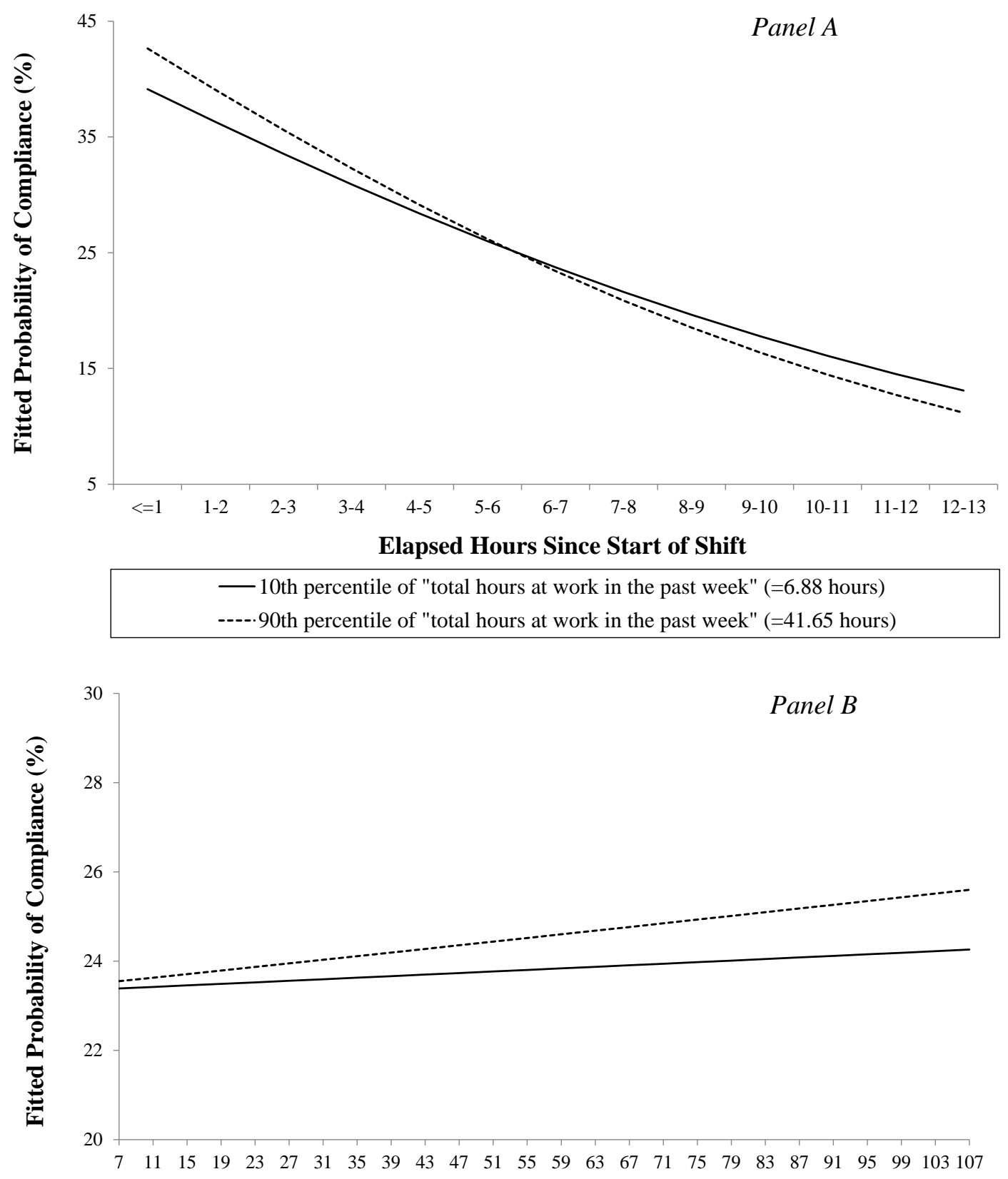

Elapsed Hours Since Last Shift

10th percentile of "total hours at work in the past week" (=6.88 hours) ---.90th percentile of "total hours at work in the past week" (=41.65 hours) 


\section{Appendix A: Data Exclusion Criteria}

As mentioned in the paper (page 15), our dataset documents 14,286,448 unique hand hygiene opportunities in total. We dropped a number of problematic observations before analyzing these data. First, we eliminated hand hygiene opportunities that did not occur in patient rooms but instead occurred in hospital locations where patient safety guidelines vary regarding the need for sanitation (e.g., hospital kitchens, cleaning rooms, storage rooms; $N=63,972$ ). ${ }^{1}$ Second, we dropped hand hygiene opportunities generated by Proventix employees who helped maintain a hospitals' monitoring system but were not healthcare workers $(N=2,590)$. We also excluded three hospital units for which only a few weeks of data were available. These units had just started testing Proventix's systems with a small subset of employees at the time of our data collection and thus were quite atypical $(N=7,578)$. Additionally, we deleted (rare) observations that appeared to contain data errors (i.e., identical, duplicate episodes recorded for the same caregiver; entrances into a new patient's room before an exit was recorded from the previous room; $\mathrm{N}=2,354)$. However, relaxing any of these criteria for improving the quality and reliability of our data would not meaningfully influence the statistical significance of our results.

\footnotetext{
${ }^{1}$ One hospital unit was entirely eliminated from our data set when we dropped observations occurring outside of patient rooms because all hand hygiene opportunities in that unit occurred in a cleaning room $(N=4,906)$.
} 


\section{Appendix B: Robustness Tests}

The regression results presented in Table 3 remained meaningfully unchanged in terms of magnitude and statistical significance when we performed a host of robustness checks, which are detailed below. All regression results reported in this section are available from the authors upon request.

1. Our findings were robust to various alternative specifications including: (a) ordinary least square regression models where fixed effects for each caregiver are included and standard errors are clustered at the hospital level or at the caregiver level, (b) two-level random intercept logistic regression models with caregiver random effects, and (c) two-level random intercept logistic regression models with caregiver random effects and hospital fixed effects. These additional regression results are included in Appendix F.

2. Our findings were robust to inferring that a shift ends when eight, nine, ten, eleven, or twelve hours separated two subsequent episodes in our data instead of relying on a seven hour shift segmentation rule, as we did in our primary analyses.

3. Our findings were robust to including all shifts lasting fewer than 36 hours in our analysis (instead of focusing on normal shifts lasting no longer than 13 hours).

4. It is plausible that caregivers washed their hands at a particularly high rate the first time they entered a patient's room during a shift because they had just entered the hospital. Therefore, we repeated our analyses but excluded either (a) each caregiver's first hand hygiene opportunity on a given shift or (b) all hand hygiene opportunities occurring within the first hour of a given caregiver's shift. Our results were robust to the imposition of these data restrictions. As explained in footnote 10 of the paper (page 20), our measures of work intensity by our definition will have high values at the beginning of a shift if the first few 
episodes are very short. The robustness checks described here help rule out the possibility that extremely short episodes at the beginning of a shift could distort our findings.

5. About $36 \%$ of shifts in our data set lasted no longer than eight hours: the minimum length of a normal shift for full-time caregivers. These short shifts may reflect the fact that we underestimated shift lengths because we did not observe workers' activities outside of patients' rooms. Alternatively, however, some short shifts may be unusual and/or attributable to caregivers receiving unexpected calls to come to the hospital due to an emergency. To address the possibility that these atypically short shifts drive our results, we re-ran our analysis with only shifts that lasted at least eight hours and found that our results were robust.

6. We re-ran each model in Table 3 separately for hand hygiene opportunities associated with room entrances and room exits. When we conducted these separate entrance and exit analyses, we found consistent support for our hypotheses with both types of compliance opportunities.

7. Our results were robust to analyzing our data at the episode level using a trichotomous dependent variable, which we set equal to two if a caregiver washed her hands both upon entering and exiting a room, one if a caregiver washed her hands either upon entry or exit but not both, or zero if no hand cleansing was observed upon room entry or room exit.

8. As would be expected given their frequent interactions with patients, nurses and patient care technicians generated $91 \%$ of all observed hand hygiene opportunities. If we analyzed our data examining only nurses and patient care technicians, all of the results reported in this paper would remain meaningfully unchanged. 
9. We changed our definition of the maximum break length included in our analyses. We examined breaks that lasted up to two weeks, one week, three days or two days rather than 108 hours (4.5 days) and found the same basic relationship between break length and hand hygiene compliance rates reported in Table 3, Models 5, 6, and 8.

10. We also conducted robustness tests on our analyses of the spillover effects of accumulated work demands on compliance during caregivers' subsequent work shifts. Our results reported in Table 3, Models 7 and 8, remained meaningfully unchanged if we replaced total hours at work in the past week with the total number of hours worked in the past 14 days (i.e., two weeks), in the past five days (the typical number of workdays per week) or within an even shorter time window (including two, three, or four days) prior to the start of a given shift. 


\section{Appendix C: Summary Statistics Describing Hospital Characteristics}

Statistics describing the hospital units were provided for most but not all sites. ${ }^{2}$ Of the 34 hospitals for which detailed descriptive information was available, 23 were located in Alabama, and the remaining 11 hospitals were spread across six other U.S. states (Arizona, California, New Jersey, Pennsylvania, Tennessee, and Texas). Twenty-five of these hospitals were located in urban areas, and nine were in rural areas. The number of staffed beds across hospitals ranged from 50 to $1,097(M=287, S D=242)$. Of the 53 hospital units for which descriptive statistics were provided, $49 \%$ were adult medical-surgical wards, and $36 \%$ were adult critical care units. The remaining units included one emergency department, two labor-and-delivery departments, three oncology departments, and two orthopedics departments. Our data also included short titles describing the work role of each caregiver. Using these short titles, we determined that $65 \%$ of our sample consisted of nurses (e.g., nurse practitioners, nurse supervisors, and registered nurses) and $12 \%$ were patient care technicians. ${ }^{3}$ The remaining caregivers included therapists (e.g., respiratory therapists, physical therapists; $7 \%$ ), physicians (4\%), and a handful of other types of employees (e.g., clinical directors, infection preventionists, etc.).

\footnotetext{
${ }^{2}$ Information on the state where a hospital is located and hospital unit function was available for 34 hospitals and 53 hospital units. Information on the number of staffed beds in a hospital was available for 33 hospitals. All summary statistics reported here were calculated based on the hospital units with available information.

${ }^{3}$ Patient care technicians work under the supervision of a registered nurse, physician, or other health professional to provide basic patient care, including taking vital signs, obtaining blood and urine samples, performing basic diagnostic tests and so on.
} 
Appendix D: Description of Control Variables Included in Our Primary Regression Analyses

Name Description

Prior research suggests that caregivers' duration of contact with patients

Episode matters: caregivers who are in contact with patients for more than two minutes

Duration (in are more likely to wash their hands than caregivers who are in contact with

hours) patients for less than two minutes (WHO, 2009). Thus, we control for the duration of each episode.

Several studies have shown that compliance with hand hygiene guidelines is

Room Entry lower prior to patient care than following patient care (WHO, 2009). We

Indicator construct an indicator variable that is equal to one if a hand hygiene opportunity occurs at room entry; otherwise, this indicator is set equal to zero.

Caregivers tend to increase their hand hygiene compliance the longer they work

Days Since First for a hospital (WHO, 2009). To account for potential time trends in compliance

Caregiver following the initiation of Proventix's caregiver monitoring system, we

Observation construct a variable equal to the number of days that had elapsed since a caregiver first appeared in the Proventix dataset.

For each hospital unit studied, most observations occurred after the unit's "badge date", or the date when the Proventix monitoring system went into

Post-monitoring effect for all caregivers in the unit. However, some observations occurred Indicator before a unit's badge date for two reasons. First, a small number of caregivers received a badge embedded with an RFID chip before the Proventix system was officially rolled out in their unit (i.e., before the badge date). Second, caregivers who worked in a unit that started individual tracking earlier occasionally 
worked in another unit that had installed Proventix's dispensers but had not yet started individual tracking. To control for the possibility that caregivers complied with hand hygiene guidelines differentially before and after a unit's official badge date, we construct an indicator variable that is set equal to one if a hand hygiene opportunity occurred on or after a given unit's badge date and is otherwise set equal to zero.

To control for the possibility that workflow differs at different times of the day or that people's daily circadian rhythms influence their energy levels and Hour of the Day attentional resources (Babkoff, Caspy, Mikulincer, \& Sing, 1991) , we $^{4}$ construct indicator variables for each hour in the 24 hour clock (0:00 hours through 23:00 hours; 0:00 hours is the omitted indicator in our analyses). To control for the previous observation that workers wash their hands less Day of the Week frequently during the week than on weekends (WHO, 2009), we construct indicator variables for each day of the week (Tuesday through Sunday; Monday is the omitted indicator in our analyses).

To control for the possibility of seasonality in compliance rates, we construct

Month Indicator indicator variables for each month of the year (February through December; January is the omitted indicator in our analyses).

To control for any changes in compliance over time, we construct indicators for Year Indicator $\quad$ the year when each hand hygiene opportunity occurred (2011 through 2013; 2010 is the omitted indicator in our analyses).

${ }^{4}$ Babkoff, H. Caspy, T. Mikulincer, M. Sing, H. C. (1991). Monotonic and rhythmic influences: A challenge for sleep deprivation research. Psychological Bulletin, 109, 411-428. doi: 10.1037/0033-2909.109.3.411 
Appendix E: Regression Results Based on Alternative Analysis Strategies

Table A1: Regression Results from Ordinary Least Squares Regression Models (with Standard Errors Clustered at the Hospital Level)

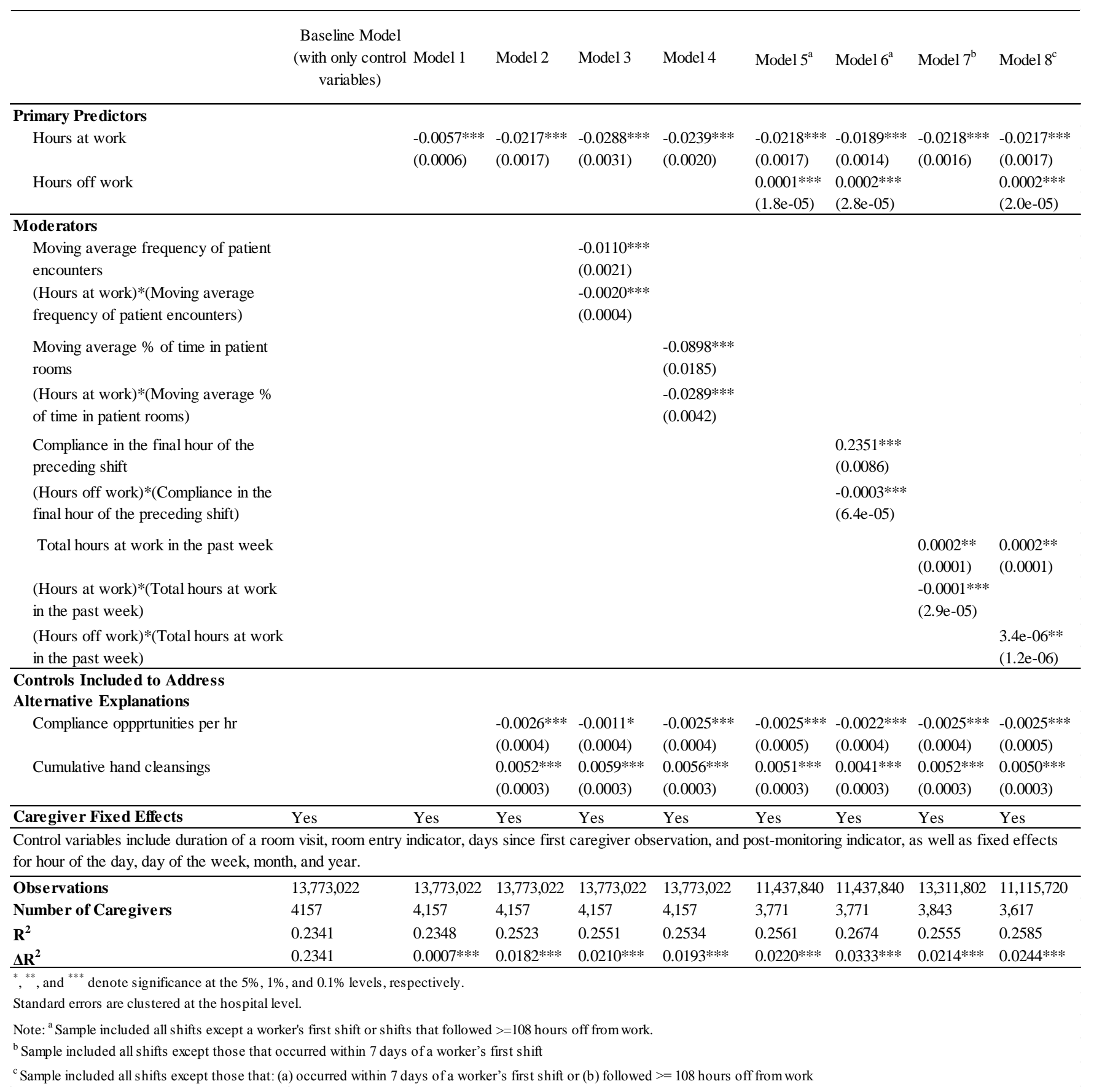


Table A2: Regression Results from Ordinary Least Squares Regression Models (with Standard

\section{Errors Clustered at the Caregiver Level)}

\begin{tabular}{|c|c|c|c|c|c|c|c|c|c|}
\hline & $\begin{array}{c}\text { Baseline Model } \\
\text { (with only control } \\
\text { variables) }\end{array}$ & Model 1 & Model 2 & Model 3 & Model 4 & Model $5^{\mathrm{a}}$ & Model $6^{\mathrm{a}}$ & Model $7^{\mathrm{b}}$ & Model $8^{\mathrm{c}}$ \\
\hline \multicolumn{10}{|l|}{ Primary Predictors } \\
\hline Hours at work & & $\begin{array}{l}-0.0057 * * * \\
(0.0003)\end{array}$ & $\begin{array}{l}-0.0217 * * * \\
(0.0005)\end{array}$ & $\begin{array}{l}-0.0288^{* * * *} \\
(0.0009)\end{array}$ & $\begin{array}{l}-0.0239 * * * \\
(0.0006)\end{array}$ & $\begin{array}{l}-0.0218^{* * * *} \\
(0.0005)\end{array}$ & $\begin{array}{l}-0.0189 * * * \\
(0.0005)\end{array}$ & $\begin{array}{l}-0.0218^{* * * *} \\
(0.0005)\end{array}$ & $\begin{array}{l}-0.0217 * * * \\
(0.0006)\end{array}$ \\
\hline Hours off work & & & & & & $\begin{array}{l}0.0001 * * * \\
(1.2 \mathrm{e}-05)\end{array}$ & $\begin{array}{l}0.0002 * * * \\
(1.3 \mathrm{e}-05) \\
\end{array}$ & & $\begin{array}{l}0.0002^{* * * *} \\
(1.3 \mathrm{e}-05)\end{array}$ \\
\hline \multicolumn{10}{|l|}{ Moderators } \\
\hline $\begin{array}{l}\text { Moving average frequency of patient } \\
\text { encounters }\end{array}$ & & & & $\begin{array}{l}-0.0110 * * * \\
(0.0008)\end{array}$ & & & & & \\
\hline (Hours at work)*(Moving average & & & & $-0.0020 * * *$ & & & & & \\
\hline frequency of patient encounters) & & & & $(0.0002)$ & & & & & \\
\hline $\begin{array}{l}\text { Moving average } \% \text { of time in patient } \\
\text { rooms }\end{array}$ & & & & & $\begin{array}{l}-0.0898 * * * \\
(0.0060)\end{array}$ & & & & \\
\hline $\begin{array}{l}\text { (Hours at work)*(Moving average } \% \\
\text { of time in patient rooms) }\end{array}$ & & & & & $\begin{array}{l}-0.0289 * * * \\
(0.0014)\end{array}$ & & & & \\
\hline $\begin{array}{l}\text { Compliance in the final hour of the } \\
\text { preceding shift }\end{array}$ & & & & & & & $\begin{array}{l}0.2351 * * * \\
(0.0045)\end{array}$ & & \\
\hline $\begin{array}{l}\text { (Hours off work)*(Compliance in the } \\
\text { final hour of the preceding shift) }\end{array}$ & & & & & & & $\begin{array}{l}-0.0003 * * * \\
(4.0 \mathrm{e}-05)\end{array}$ & & \\
\hline Total hours at work in the past week & & & & & & & & $\begin{array}{l}0.0002 * * \\
(4.9 \mathrm{e}-05)\end{array}$ & $\begin{array}{l}0.0002 * * \\
(0.0001)\end{array}$ \\
\hline $\begin{array}{l}\text { (Hours at work)*(Total hours at work } \\
\text { in the past week) }\end{array}$ & & & & & & & & $\begin{array}{l}-0.0001 * * * \\
(1.3 \mathrm{e}-05)\end{array}$ & \\
\hline $\begin{array}{l}\text { (Hours off work)*(Total hours at work } \\
\text { in the past week) }\end{array}$ & & & & & & & & & $\begin{array}{l}3.4 \mathrm{e}-06^{* *} \\
(1.1 \mathrm{e}-06) \\
\end{array}$ \\
\hline \multicolumn{10}{|l|}{$\begin{array}{l}\text { Controls Included to Address } \\
\text { Alternative Explanations }\end{array}$} \\
\hline Compliance oppprtunities per $\mathrm{hr}$ & & & $\begin{array}{l}-0.0026^{* * *} \\
(0.0002)\end{array}$ & $\begin{array}{l}-0.0011^{*} \\
(0.0002)\end{array}$ & $\begin{array}{l}-0.0025^{* * *} \\
(0.0002)\end{array}$ & $\begin{array}{l}-0.0025^{* * *} \\
(0.0002)\end{array}$ & $\begin{array}{l}-0.0022 * * * \\
(0.0002)\end{array}$ & $\begin{array}{l}-0.0025 * * * \\
(0.0002)\end{array}$ & $\begin{array}{l}-0.0025^{* * *} \\
(0.0002)\end{array}$ \\
\hline Cumulative hand cleansings & & & $\begin{array}{l}0.0052 * * * \\
(0.0002)\end{array}$ & $\begin{array}{l}0.0059 * * * \\
(0.0002)\end{array}$ & $\begin{array}{l}0.0056^{* * * *} \\
(0.0002)\end{array}$ & $\begin{array}{l}0.0051^{* * * *} \\
(0.0002)\end{array}$ & $\begin{array}{l}0.0041^{* * *} \\
(0.0002)\end{array}$ & $\begin{array}{l}0.0052 * * * \\
(0.0002)\end{array}$ & $\begin{array}{l}0.0050^{* * * *} \\
(0.0002)\end{array}$ \\
\hline Caregiver Fixed Effects & Yes & Yes & Yes & Yes & Yes & Yes & Yes & Yes & Yes \\
\hline \multicolumn{10}{|c|}{$\begin{array}{l}\text { Control variables include duration of a room visit, room entry indicator, days since first caregiver observation, and post-monitoring indicator, as well as fixed effects } \\
\text { for hour of the day, day of the week, month, and year. }\end{array}$} \\
\hline Observations & $13,773,022$ & $13,773,022$ & $13,773,022$ & $13,773,022$ & $13,773,022$ & $11,437,840$ & $11,437,840$ & $13,311,802$ & $11,115,720$ \\
\hline Number of Caregivers & 4157 & 4,157 & 4,157 & 4,157 & 4,157 & 3,771 & 3,771 & 3,843 & 3,617 \\
\hline $\mathbf{R}^{2}$ & 0.2341 & 0.2348 & 0.2523 & 0.2551 & 0.2534 & 0.2561 & 0.2674 & 0.2555 & 0.2585 \\
\hline$\Delta \mathbf{R}^{2}$ & 0.2341 & $0.0007 * * *$ & $0.0182 * * *$ & $0.0210 * * *$ & $0.0193^{* * *}$ & $0.0220 * * *$ & $0.0333 * * *$ & $0.0214 * * *$ & $0.0244 * * *$ \\
\hline \multicolumn{10}{|c|}{${ }^{* * *}$, and $^{* * *}$ denote significance at the $5 \%, 1 \%$, and $0.1 \%$ levels, respectively. } \\
\hline
\end{tabular}


Table A3: Regression Results from Two-level Random Intercept Logistic Regression Models

\begin{tabular}{|c|c|c|c|c|c|c|c|c|}
\hline & Model 1 & Model 2 & Model 3 & Model 4 & Model $5^{\mathrm{a}}$ & Model $6^{\mathrm{a}}$ & Model $7^{\mathrm{b}}$ & Model $8^{\mathrm{c}}$ \\
\hline \multicolumn{9}{|l|}{ Primary Predictors } \\
\hline Hours at work & $\begin{array}{l}-0.0316^{* * * *} \\
(0.0014)\end{array}$ & $\begin{array}{l}-0.1347 * * * \\
(0.0027)\end{array}$ & $\begin{array}{l}-0.2368 * * * \\
(0.0056)\end{array}$ & $\begin{array}{l}-0.1519 * * * \\
(0.0030)\end{array}$ & $\begin{array}{l}-0.1350 * * * \\
(0.0028)\end{array}$ & $\begin{array}{l}-0.1200^{* * * *} \\
(0.0025)\end{array}$ & $\begin{array}{l}-0.1348^{* * * *} \\
(0.0027)\end{array}$ & $\begin{array}{l}-0.1343 * * * \\
(0.0029)\end{array}$ \\
\hline Hours off work & & & & & $\begin{array}{l}0.0007 * * * \\
(0.0001) \\
\end{array}$ & $\begin{array}{l}0.0011 * * * \\
(0.0001) \\
\end{array}$ & & $\begin{array}{l}0.0008 * * * \\
(0.0001)\end{array}$ \\
\hline \multicolumn{9}{|l|}{ Moderators } \\
\hline $\begin{array}{l}\text { Moving average frequency of patient } \\
\text { encounters } \\
\text { (Hours at work)*(Moving average } \\
\text { frequency of patient encounters) }\end{array}$ & & & $\begin{array}{l}-0.1298 * * * \\
(0.0052) \\
-0.0247 * * * \\
(0.0010)\end{array}$ & & & & & \\
\hline $\begin{array}{l}\text { Moving average } \% \text { of time in patient } \\
\text { rooms }\end{array}$ & & & & $\begin{array}{l}-0.6497 * * * \\
(0.0329)\end{array}$ & & & & \\
\hline $\begin{array}{l}\text { (Hours at work)*(Moving average } \% \text { of } \\
\text { time in patient rooms) }\end{array}$ & & & & $\begin{array}{l}-0.1751^{* * *} \\
(0.0073)\end{array}$ & & & & \\
\hline $\begin{array}{l}\text { Compliance in the final hour of the } \\
\text { preceding shift }\end{array}$ & & & & & & $\begin{array}{l}1.0651 * * * \\
(0.0199)\end{array}$ & & \\
\hline $\begin{array}{l}\text { (Hours off work)*(Compliance in the } \\
\text { final hour of the preceding shift) }\end{array}$ & & & & & & $\begin{array}{l}-0.0025 * * * \\
(0.0002)\end{array}$ & & \\
\hline Total hours at work in the past week & & & & & & & $\begin{array}{l}0.0010 * * * \\
(0.0003)\end{array}$ & $\begin{array}{l}0.0014 * * * \\
(0.0003)\end{array}$ \\
\hline $\begin{array}{l}\text { (Hours at work)*(Total hours at work in } \\
\text { the past week) }\end{array}$ & & & & & & & $\begin{array}{l}-0.0008 * * * \\
(0.0001)\end{array}$ & \\
\hline $\begin{array}{l}\text { (Hours off work)*(Total hours at work in } \\
\text { the past week) }\end{array}$ & & & & & & & & $\begin{array}{l}1.8 \mathrm{e}-05^{* *} \\
(6.0 \mathrm{e}-06)\end{array}$ \\
\hline \multicolumn{9}{|l|}{$\begin{array}{l}\text { Controls Included to Address } \\
\text { Alternative Explanations }\end{array}$} \\
\hline Compliance oppprtunities per $\mathrm{hr}$ & & $\begin{array}{l}-0.0189 * * * \\
(0.0011)\end{array}$ & $\begin{array}{l}-0.0063^{* * * *} \\
(0.0011)\end{array}$ & $\begin{array}{l}-0.0182 * * * \\
(0.0011)\end{array}$ & $\begin{array}{l}-0.0182 * * * \\
(0.0012)\end{array}$ & $\begin{array}{l}-0.0167 * * * \\
(0.0011)\end{array}$ & $\begin{array}{l}-0.0188 * * * \\
(0.0012)\end{array}$ & $\begin{array}{l}-0.0181 * * * \\
(0.0012)\end{array}$ \\
\hline Cumulative hand cleansings & & $\begin{array}{l}0.0310 * * * \\
(0.0010)\end{array}$ & $\begin{array}{l}0.0422 * * * \\
(0.0011)\end{array}$ & $\begin{array}{l}0.0339 * * * \\
(0.0010)\end{array}$ & $\begin{array}{l}0.0303 * * * \\
(0.0010)\end{array}$ & $\begin{array}{l}0.0254 * * * \\
(0.0009)\end{array}$ & $\begin{array}{l}0.0308 * * * \\
(0.0010)\end{array}$ & $\begin{array}{l}0.0300 * * * \\
(0.0010)\end{array}$ \\
\hline \multicolumn{9}{|c|}{$\begin{array}{l}\text { Control variables include duration of a room visit, room entry indicator, days since first caregiver observation, and post-monitoring indicator, as well as } \\
\text { fixed effects for hour of the day, day of the week, month, and year. }\end{array}$} \\
\hline Observations & $13,773,022$ & $13,773,022$ & $13,773,022$ & $13,773,022$ & $11,437,840$ & $11,437,840$ & $13,311,802$ & $11,115,720$ \\
\hline Number of Caregivers & 4,157 & 4,157 & 4,157 & 4,157 & 3,771 & 3,771 & 3,843 & 3,617 \\
\hline
\end{tabular}

${ }^{*},{ }^{* *}$, and ${ }^{* * *}$ denote significance at the $5 \%, 1 \%$, and $0.1 \%$ levels, respectively.

Note: ${ }^{a}$ Sample included all shifts except a worker's first shift or shifts that followed $>=108$ hours off from work.

${ }^{\mathrm{b}}$ Sample included all shifts except those that occurred within 7 days of a worker's first shift

${ }^{\mathrm{c}}$ Sample included all shifts except those that: (a) occurred within 7 days of a worker's first shift or (b) followed $>=108$ hours off from work 
Table A4: Regression Results from Two-level Random Intercept Logistic Regression Models with Hospital Fixed Effects

\begin{tabular}{|c|c|c|c|c|c|c|c|c|}
\hline & Model 1 & Model 2 & Model 3 & Model 4 & Model $5^{\text {a }}$ & Model $6^{\mathrm{a}}$ & Model $7^{\mathrm{b}}$ & Model $8^{\mathrm{c}}$ \\
\hline \multicolumn{9}{|l|}{ Primary Predictors } \\
\hline Hours at work & $\begin{array}{l}-0.0316 * * * \\
(0.0014)\end{array}$ & $\begin{array}{l}-0.1347 * * * \\
(0.0027)\end{array}$ & $\begin{array}{l}-0.2368 * * * \\
(0.0056)\end{array}$ & $\begin{array}{l}-0.1518 * * * \\
(0.0030)\end{array}$ & $\begin{array}{l}-0.1350 * * * \\
(0.0028)\end{array}$ & $\begin{array}{l}-0.1199 * * * \\
(0.0025)\end{array}$ & $\begin{array}{l}-0.1348 * * * \\
(0.0027)\end{array}$ & $\begin{array}{l}-0.1343 * * * \\
(0.0029)\end{array}$ \\
\hline Hours off work & & & & & $\begin{array}{l}0.0007 * * * \\
(0.0001)\end{array}$ & $\begin{array}{l}0.0011 * * * \\
(0.0001)\end{array}$ & & $\begin{array}{l}0.0008 * * * \\
(0.0001)\end{array}$ \\
\hline \multicolumn{9}{|l|}{ Moderators } \\
\hline $\begin{array}{l}\text { Moving average frequency of patient } \\
\text { encounters }\end{array}$ & & & $\begin{array}{l}-0.1298 * * * \\
(0.0052)\end{array}$ & & & & & \\
\hline $\begin{array}{l}\text { (Hours at work)*(Moving average } \\
\text { frequency of patient encounters) }\end{array}$ & & & $\begin{array}{l}-0.0247 * * * \\
(0.0010)\end{array}$ & & & & & \\
\hline $\begin{array}{l}\text { Moving average } \% \text { of time in patient } \\
\text { rooms }\end{array}$ & & & & $\begin{array}{l}-0.6500 * * * \\
(0.0329)\end{array}$ & & & & \\
\hline $\begin{array}{l}\text { (Hours at work) } *(\text { Moving average } \% \text { of } \\
\text { time in patient rooms) }\end{array}$ & & & & $\begin{array}{l}-0.1751^{* * *} \\
(0.0073)\end{array}$ & & & & \\
\hline $\begin{array}{l}\text { Compliance in the final hour of the } \\
\text { preceding shift }\end{array}$ & & & & & & $\begin{array}{l}1.0646^{* * * *} \\
(0.0199)\end{array}$ & & \\
\hline $\begin{array}{l}\text { (Hours off work)*(Compliance in the } \\
\text { final hour of the preceding shift) }\end{array}$ & & & & & & $\begin{array}{l}-0.0025 * * * \\
(0.0002)\end{array}$ & & \\
\hline Total hours at work in the past week & & & & & & & $\begin{array}{l}0.0010^{* * * *} \\
(0.0003)\end{array}$ & $\begin{array}{l}0.0014 * * * \\
(0.0003)\end{array}$ \\
\hline $\begin{array}{l}\text { (Hours at work)*(Total hours at work in } \\
\text { the past week) }\end{array}$ & & & & & & & $\begin{array}{l}-0.0008 * * * \\
(0.0001)\end{array}$ & \\
\hline $\begin{array}{l}\text { (Hours off work)*(Total hours at work in } \\
\text { the past week) }\end{array}$ & & & & & & & & $\begin{array}{l}1.8 \mathrm{e}-05^{* *} \\
(6.0 \mathrm{e}-06)\end{array}$ \\
\hline \multicolumn{9}{|l|}{$\begin{array}{l}\text { Controls Included to Address } \\
\text { Alternative Explanations }\end{array}$} \\
\hline Compliance oppprtunities per $\mathrm{hr}$ & & $\begin{array}{l}-0.0189 * * * \\
(0.0011)\end{array}$ & $\begin{array}{l}-0.0063 * * * \\
(0.0011)\end{array}$ & $\begin{array}{l}-0.0181 * * * \\
(0.0011)\end{array}$ & $\begin{array}{l}-0.0182 * * * \\
(0.0012)\end{array}$ & $\begin{array}{l}-0.0167 * * * \\
(0.0011)\end{array}$ & $\begin{array}{l}-0.0188 * * * \\
(0.0012)\end{array}$ & $\begin{array}{l}-0.0181 * * * \\
(0.0012)\end{array}$ \\
\hline Cumulative hand cleansings & & $\begin{array}{l}0.0310 * * * \\
(0.0010)\end{array}$ & $\begin{array}{l}0.0422 * * * \\
(0.0011)\end{array}$ & $\begin{array}{l}0.0339 * * * \\
(0.0010)\end{array}$ & $\begin{array}{l}0.0303 * * * \\
(0.0010)\end{array}$ & $\begin{array}{l}0.0254 * * * \\
(0.0009)\end{array}$ & $\begin{array}{l}0.0308 * * * \\
(0.0010)\end{array}$ & $\begin{array}{l}0.0299 * * * \\
(0.0010)\end{array}$ \\
\hline
\end{tabular}

Control variables include duration of a room visit, room entry indicator, days since first caregiver observation, and post-monitoring indicator, as well as fixed effects for hour of the day, day of the week, month, and year.

\begin{tabular}{lllllllll}
\hline Hospital Fixed Effects & Yes & Yes & Yes & Yes & Yes & Yes & Yes & Yes \\
\hline Observations & $13,773,022$ & $13,773,022$ & $13,773,022$ & $13,773,022$ & $11,437,840$ & $11,437,840$ & $13,311,802$ & $11,115,720$ \\
Number of Caregivers & 4,157 & 4,157 & 4,157 & 4,157 & 3,771 & 3,771 & 3,843 & 3,617 \\
\hline
\end{tabular}

${ }^{* * * *}$, and ${ }^{* * * *}$ denote significance at the $5 \%, 1 \%$, and $0.1 \%$ levels, respectively.

Note: ${ }^{\text {a }}$ Sample included all shifts except a worker's first shift or shifts that followed $>=108$ hours off from work.

${ }^{\mathrm{b}}$ Sample included all shifts except those that occurred within 7 days of a worker's first shift

${ }^{\mathrm{c}}$ Sample included all shifts except those that: (a) occurred within 7 days of a worker's first shift or (b) followed $>=108$ hours off from work 
Appendix F: Calculation of Economic Cost Associated with Decreases In Hand Hygiene

\section{Compliance}

In a study of Swiss hospitals, Pittet et al. $(2000)^{5}$ found that a one percentage point increase in hand sanitation compliance rates reduces the number of infections per 1,000 admitted patients by 3.9 infections. The estimated attributable per patient cost associated with a healthcare-acquired infection is $\$ 20,549$ (Scott, 2009) $^{6}$. Thus, if the same relationships as found in Pittet et al. (2000) were to hold in our sample then the regression-estimated reduction in compliance over the course of a normal, 12-hour shift of 8.5 percentage points (based on Model 1 in Table 2) would be expected to produce an additional 33 infections per 1,000 patients at an estimated cost of $\$ 682,143$ (Scott, 2009). At an average U.S. hospital, there are 6,388 patients admitted per year (American Hospital Association Hospital Statistics, 2013) ${ }^{7}$. This suggests that the detected decrease in hand hygiene compliance during a typical work shift contributes to 212 unnecessary infections per hospital per year at a yearly cost per hospital of $\$ 4.36$ million and a cost of nearly $\$ 25$ billion annually across the 5,723 registered hospitals in the United States.

${ }^{5}$ Pittet, D., Hugonnet, S., Harbarth, S., Mourouga, P., Sauvan, V., Touveneau, S., . . Programme, I. C. (2000). Effectiveness of a hospital-wide programme to improve compliance with hand hygiene. Lancet, 356(9238), 1307-1312. doi:10.1016/S0140-6736(00)02814-2

${ }^{6}$ Scott, R.D. (2009). The direct medical costs of healthcare-associated infections in U.S. hospitals and the benefits of prevention. Available at: http://www.cdc.gov/ncidod/dhqp/pdf/Scott_CostPaper.pdf. Accessed August 2, 2013

${ }^{7}$ AHA Hospital Statistics 2013 Edition. (2012). Chicago, IL: Health Forum 